\title{
Assessing biomarker syngeneity using branched alkanes with quaternary carbon (BAQCs) and other plastic contaminants
}

\author{
Jochen J. Brocks ${ }^{\mathrm{a}, *}$, Emmanuelle Grosjean ${ }^{\mathrm{b}}$, Graham A. Logan ${ }^{\mathrm{b}}$ \\ ${ }^{a}$ Research School of Earth Sciences and Centre for Macroevolution and Macroecology, The Australian National \\ University, Canberra, ACT 0200, Australia \\ ${ }^{\mathrm{b}}$ Geoscience Australia, GPO Box 378, Canberra, ACT 2601, Australia
}

Received 17 August 2007; accepted in revised form 29 November 2007; available online 4 January 2008

\begin{abstract}
Biomarker molecules are valuable for the elucidation of ancient microbial ecosystems and the characterization of petroleum source rocks. For such studies, acquisition of reliable hydrocarbon data and proof of their syngeneity are essential. However, contamination of geological samples with anthropogenic petroleum products during drilling, storage and sampling can be particularly problematic because these hydrocarbons may over-print an original indigenous biomarker profile. To evaluate the extent of contamination of drill core and outcrop material, we studied the distribution of hydrocarbons in 26 rocks from different locations in the world. All rocks had petroleum products on their exterior surfaces. Twenty-two samples also contained surficial hydrocarbons derived from polyethylene plastic, including branched alkanes with quaternary carbon centers (BAQCs) and alkylcyclopentanes with pronounced even-over-odd carbon number preference. Using three examples from the Paleoproterozoic Tawallah and McArthur Groups in northern Australia, we show how indigenous biomarkers can be recognized by comparing hydrocarbon distributions between exterior rock surfaces and the rock interior, and how infiltration of allochthonous hydrocarbons can be assessed through the spatial distribution of characteristic polyethylene derived hydrocarbons in the rock. The methods outlined in this paper give confidence in the interpretation of biomarkers in particularly sensitive applications such as the first occurrences of certain organisms in the geological record and the provenance of organic matter in meteorites.

(C) 2007 Elsevier Ltd. All rights reserved.
\end{abstract}

\section{INTRODUCTION}

Hydrocarbon biomarkers have been routinely used in the petroleum industry since the 1970 s for assessing the organic matter of oils and sedimentary rocks and for paleoenvironmental reconstructions (Hunt et al., 2002; Durand, 2003). They are particularly important when physical fossil evidence is not available, and their application is therefore valuable for the study of Precambrian ecosystems and to provide key calibration dates for the first occurrence of organisms throughout the geological record. For instance, biomarkers have yielded the oldest dates for angiosperms (Moldowan et al., 1994) and rhizosolenid diatoms (Sinnin-

\footnotetext{
* Corresponding author.

E-mail address: jochen.brocks@anu.edu.au (J.J. Brocks).
}

ghe Damsté et al., 2004) in the Phanerozoic, and for the first occurrence of green sulfur bacteria (Chlorobiaceae) and purple sulfur bacteria (Chromatiaceae) in the Proterozoic (Brocks et al., 2005). In all of these studies it is critical to ensure that all biomarkers were originally part of the host rock and have not been incorporated at a later stage. The effort to prove the syngenetic origin of biomarkers is particularly important in the analysis of rocks with low hydrocarbon extract yields. Similar problems are also faced in studies of extra-terrestrial material; and the origin of hydrocarbons in meteorites continues to be debated (Sephton et al., 2001; Kissin, 2003).

Contaminants may come into contact with rock and sediment during collection, storage and analysis. Most synthetic contaminants such as UV absorbers, softeners and other polar additives do not pose a problem as they are easily recognized and are not likely to be confused with 
petrogenic hydrocarbons. However, many synthetic products contain at least traces of petroleum-based hydrocarbons, including biomarkers (Table 1). Hydrocarbon biomarkers in drilling fluids can have a particularly significant effect on the composition of bitumen or oil extracted from cores (Gorter, 1998; Hart and Fisher, 1998; Bennett and Larter, 2000; Wenger et al., 2004). In the case of the drilling fluid NovaPlus, the presence of biomarkers has been shown to affect the concentrations and ratios of steranes and bicyclics in a crude oil (Table 1). It is also not uncommon for drilling contractors to introduce petroleum-based lubricants into drill holes. For example, to release stuck drill pipe, diesel and Pipelax were added to the drill hole Yarra-1 (Gorter, 1998). Such additions are unfortunately rarely reported in the drilling log records. Another major contamination source that may be hard to identify are aerosols from combustion engines, including motors of drill rigs, that may settle on samples during open storage (Brocks et al., 2003a), and this type of contamination may also affect rocks collected in mines and from outcrop.

Recognizing whether a rock was tainted with petroleum derived hydrocarbons is not trivial. Therefore, it would be useful to have a molecular marker that may indicate whether a particular rock sample was susceptible to the infiltration by hydrocarbons. An ideal marker to gauge the penetration of hydrocarbons into rock are the polymerization byproducts of polyethylene plastic. Recent work has shown that polyethylene plastic bags exude a range of hydrocarbons including methylalkanes, alkylcyclohexanes, alkylcyclopentanes and branched alkanes with quaternary carbon centers (BAQCs) (Grosjean and Logan, 2007). All of these hydrocarbons, as well as $n$-alkanes, form as polymerization by-products of polyethylene (Takahashi et al., $1980 \mathrm{~b}$ ) and, with the exception of BAQCs, are also known to occur naturally in oil and bitumen. However, the polyethylene by-products can be distinguished by their exclusive predominance of either even or odd carbon homologs and the diagnostic structure of BAQCs (Takahashi et al., 1980a; Grosjean and Logan, 2007). It has also been demonstrated that BAQCs are easily transferred from storage bags to geological samples (Grosjean and Logan, 2007) where they may diffuse into fissures and pore space. As these anthropogenic hydrocarbons have adsorption and diffusion properties similar to petrogenic hydrocarbons, their presence in the interior of rocks could be a measure for susceptibility to contamination.

In recent years, BAQCs have been reported in many publications and were interpreted as biogenic despite the absence of known natural sources (for reviews see Kenig et al., 2003; Brocks and Summons, 2004; Brown and Kenig, 2004; Greenwood et al., 2004; Brocks and Pearson, 2005; Kenig et al., 2005). Kenig et al. (2003) described 12 different series with different branching positions and one or two quaternary carbon centers, including e.g. 2,2-dimethyl-,

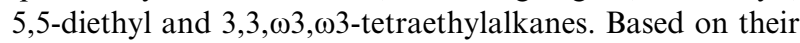
apparent occurrence in specific environments, BAQCs were construed as biomarkers for non-photosynthetic, sulfide oxidizing prokaryotes that predominantly inhabit benthic redox boundaries (Kenig et al., 2003) or identified as new proxies indicating variations in soil ecosystems and climates (Bai et al., 2006). However, a biogenic source of BAQCs can be excluded for several reasons. The structures and relative abundances of all BAQC homologs detected in geological and environmental material are virtually identical to those found in polyethylene byproducts (Takahashi et al., 1980a). As mentioned above, BAQCs are also easily transferred from polyethylene storage bags to geological samples (Grosjean and Logan, 2007), which is the reason why they are commonly concentrated on rock surfaces (this work) and are found ubiquitously in rocks and sediments from the Precambrian to the Holocene. Finally, the abundance of BAQCs relative to other hydrocarbons is highest in extracts of organically lean or metamorphosed rocks, and they are conspicuously absent from crude oil (which is commonly stored in glass vessels, not plastic). To summarize, there are no viable arguments for the biogenicity of

Table 1

Common sources of contamination

\begin{tabular}{|c|c|c|c|c|}
\hline Source & Type & Major constituents & Minor constituents & References \\
\hline Drilling fluid & NovaPlus & $\mathrm{C}_{16}, \mathrm{C}_{18}, \mathrm{C}_{20}$ branched and $n$-alkenes & Steranes, bicyclics & Hart and Fisher (1998) \\
\hline Drilling fluid & Esso Univis $\mathrm{J}-26$ & $\mathrm{C}_{10}-\mathrm{C}_{30} n$-alkanes, max. $\mathrm{C}_{12} ; \mathrm{UCM}$ & Biomarkers & Gorter (1998) \\
\hline Drilling fluid & Protectomagic & $\mathrm{C}_{10}-\mathrm{C}_{30} n$-alkanes, max. $\mathrm{C}_{12} ; \mathrm{UCM}$ & Biomarkers & Gorter (1998) \\
\hline Sunscreen & Various & UV absorbers & & Grosjean and Logan (2007) \\
\hline Lubricant & Never Seez & $\begin{array}{l}\mathrm{C}_{14}-\mathrm{C}_{21} n \text {-alkanes; UCM; } \\
\mathrm{C}_{18} \mathrm{FA} ; \mathrm{C}_{18} \text { hydroxy FA }\end{array}$ & Hopanes and steranes & Grosjean and Logan (2007) \\
\hline Wire rope grease & & $\mathrm{C}_{14}-\mathrm{C}_{36} n$-alkanes; UCM & Hopanes and steranes & Grosjean and Logan (2007) \\
\hline Whirlpak bag & Polyethylene & $\begin{array}{l}\mathrm{C}_{16}, \mathrm{C}_{18: 1} \text { FAA; butylated } \\
\text { hydroxytoluene }\end{array}$ & $\begin{array}{l}\text { BAQCs, cyclic, branched } \\
\text { and } n \text {-alkanes }\end{array}$ & $\begin{array}{l}\text { Takahashi et al. (1980a,b) } \\
\text { and Grosjean and Logan (2007) }\end{array}$ \\
\hline Kaltex bag & Polyethylene & $\mathrm{C}_{22: 1}$ FAA; Irganox & $\begin{array}{l}\text { BAQCs, cyclic, branched } \\
\text { and } n \text {-alkanes }\end{array}$ & $\begin{array}{l}\text { Takahashi et al. (1980a,b) } \\
\text { and Grosjean and Logan (2007) }\end{array}$ \\
\hline Diesel aerosol & $\begin{array}{l}\text { Vehicles, drilling } \\
\text { equipment }\end{array}$ & $\mathrm{C}_{11}-\mathrm{C}_{25} n$-alkanes, max. $\mathrm{C}_{16}-\mathrm{C}_{18}$ & Biomarkers & Brocks et al. (2003a) \\
\hline $\begin{array}{l}\text { Plastic bottles and } \\
\text { containers }\end{array}$ & Polypropylene & & $\begin{array}{l}\mathrm{C}_{3 n} \text { highly branched } \\
\text { alkanes }\end{array}$ & Greenwood (2006) \\
\hline Rock grinding & & $\begin{array}{l}\text { Cross-contamination; } \\
\text { cholesterol; squalene; FA }\end{array}$ & Biomarkers & \\
\hline Solvents & & Petrogenic hydrocarbons & Biomarkers & \\
\hline
\end{tabular}


these compounds, and an anthropogenic origin appears certain.

The aim of this paper is to illustrate how these contaminants from polyethylene storage bags can be turned into an advantage by yielding information about the permeability of rock to petroleum products. We present data from three case studies from the 1.64-Ga McArthur Group in northern Australia to demonstrate how the spatial distribution of polyethylene by-products in drill core is used to obtain information about biomarker syngeneity.

\section{METHODS}

\subsection{Interior/exterior experiments}

To analyze concentration differences of hydrocarbons and other compounds between the exterior surfaces of a rock and its interior, all rock surfaces were trimmed using a clean precision wafering saw (Buehler Isomet 1000; blade thickness 340 or $460 \mu \mathrm{m}$ ) according to the patterns shown in Fig. 1. The combined surface material and the remaining rock core were separately crushed to powder, extracted and fractionated as described under 'processing of rock samples'.

\subsection{Slice-extraction experiments}

To analyze millimeter-scale concentration gradients of hydrocarbons in rock, $\sim 1.5-3 \mathrm{~cm}$ blocks of shale were cut from diamond drill cores, including the exterior rounded surface and the center of the core. The shale was not cleaned or treated with solvents prior to analysis. The blocks were then cut into $1-\mathrm{mm}$ slices with a clean precision saw (Buehler Isomet 1000; blade thickness 340 or $460 \mu \mathrm{m}$ ) parallel to the outer rounded surface and perpendicular to the bedding direction. Between each cut, the cutting water was changed and the wafering blade cleaned using purified water and solvents.

\subsection{Processing of rock samples}

The rock material was ultrasonicated in distilled water for $10 \mathrm{~s}$ to remove particulates, dried at room temperature and ground to $>200$ mesh grain size in an alumina ring-mill. The mill was cleaned between samples by grinding annealed quartz sand two to three times for $60 \mathrm{~s}$. Rock powder was extracted with dichloromethane (DCM):methanol $(9: 1, \mathrm{v} / \mathrm{v})$ with a Dionex Accelerated Solvent Extractor. The extracts were reduced to $100 \mu$ under a stream of purified nitrogen gas and separated into saturated, aromatic and polar fractions using column chromatography over $12 \mathrm{~g}$ annealed $\left(450{ }^{\circ} \mathrm{C} / 24 \mathrm{~h}\right)$ and dry-packed silica gel (Silica Gel 60; 230-400 mesh; EM Science). Saturated hydrocarbons were eluted with 1.5 dead volumes (DV) $n$-hexane, aromatic hydrocarbons with 2 DV $n$-hexane:DCM (1:1, $\mathrm{v} / \mathrm{v})$ and polars with $2 \mathrm{DV}$ DCM:methanol $(1: 1, \mathrm{v} / \mathrm{v})$. Added as internal standards were $\mathrm{D}_{4}\left(d_{4}-\mathrm{C}_{29}-\alpha, \alpha, \alpha\right.$-ethylcholestane; Chiron Laboratories AS) to the saturated hydrocarbon fraction, $d_{14}\left(d_{14}\right.$-para-terphenyl, 98 at. $\%$ deuterium; Aldrich Chemical Co.) to the aromatic hydrocarbon fraction and 3-methylheneicosane to the polar fraction. The extracts were analyzed and quantified by GC-MS.

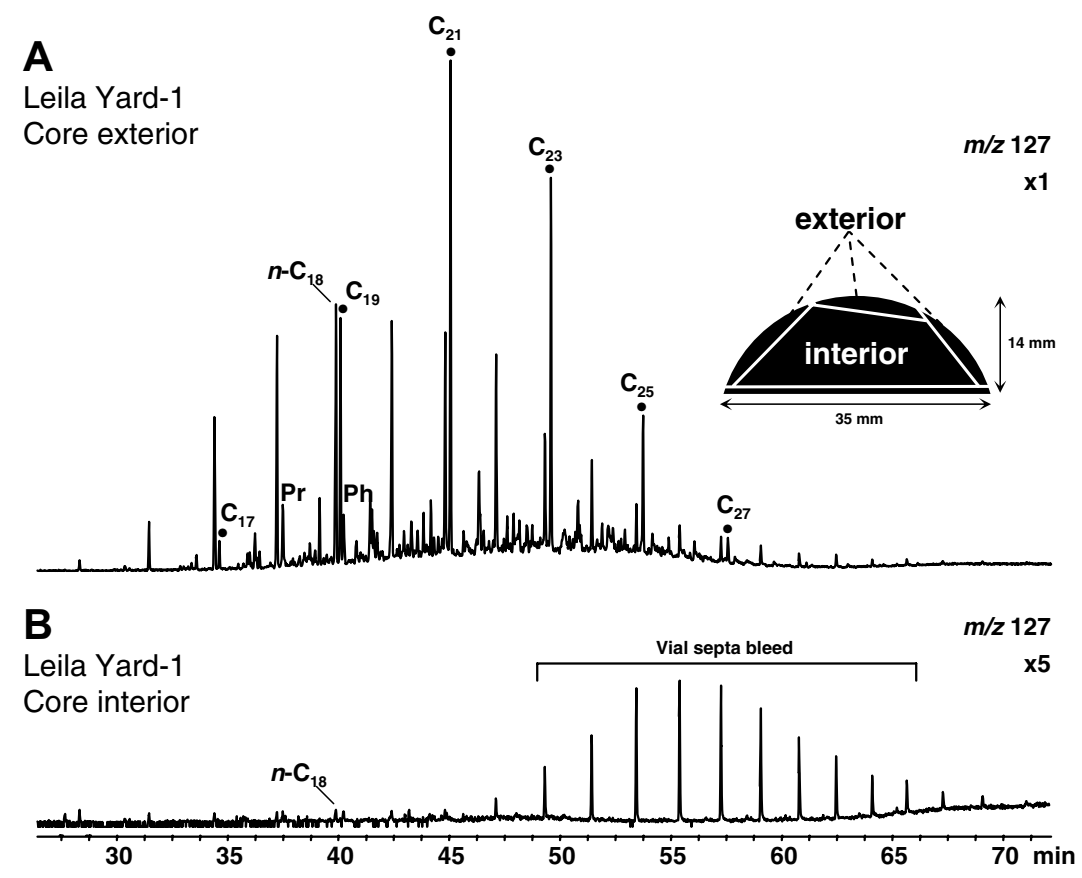

Fig. 1. Partial mass chromatograms $m / z 127$ of the saturated hydrocarbon fractions of sample B03288 (drill core LY-1, 403.54 m, Barney Creek Formation, McArthur Basin). (A) Exterior portion of the drill core, (B) interior. Signal heights were normalized to extract yields per gram of rock, and ' $\times 5$ ' indicates magnification of the trace. $\bullet$, 5,5-DEA BAQC series; Pr, pristane; Ph, phytane. 


\subsection{Bulk characteristics}

Kerogen contents (TOC) and ROCK-EVAL parameters were determined on VINCI ROCK-EVAL 6 instrument according to established procedures (Espitalié et al., 1977).

\subsection{Gas chromatography-mass spectroscopy (GC-MS)}

GC-MS analyses of the saturated and aromatic fractions were carried out on Micromass AutoSpec Ultima or AutoSpec Premier equipped with HP6890 gas chromatograph (Hewlett Packard) and a DB-1 or DB-5 capillary column ( $60 \mathrm{~m} \times 0.25 \mathrm{~mm}$ i.d., $0.25 \mu \mathrm{m}$ film thickness) using $\mathrm{He}$ as carrier gas. The MS source was operated at $250{ }^{\circ} \mathrm{C}$ in EImode at $70 \mathrm{eV}$ ionization energy and with $8000 \mathrm{~V}$ acceleration voltage. Hydrocarbon fractions were injected in pulsed splitless mode into a Gerstel PTV injector at a constant temperature of $300{ }^{\circ} \mathrm{C}$. For full-scan and selected ion recording (SIR) experiments, the $\mathrm{GC}$ oven was programmed at $60^{\circ} \mathrm{C}(2 \mathrm{~min})$, heated to $315^{\circ} \mathrm{C}$ at $4{ }^{\circ} \mathrm{C} / \mathrm{min}$, with a final hold time of $35 \mathrm{~min}$. Hopane and sterane biomarkers were analyzed by metastable reaction monitoring (MRM) with a total cycle time of $1.3 \mathrm{~s}$ per scan for 25 metastable transitions. For MRM, the GC oven was programmed at $60^{\circ} \mathrm{C}(2 \mathrm{~min})$, heated to $100^{\circ} \mathrm{C}$ at $8{ }^{\circ} \mathrm{C} / \mathrm{min}$, further heated to $315^{\circ} \mathrm{C}$ at $4{ }^{\circ} \mathrm{C} / \mathrm{min}$ and hold at the final temperature for $34 \mathrm{~min}$.

The polar fraction was derivatized with $\mathrm{N}, \mathrm{O}$-bis(trimethylsilyl)trifluoroacetamide (BSTFA) and analyzed using a Hewlett Packard Mass Selective Detector 5973 equipped with a HP6890 gas chromatograph and a DB-1 capillary column $(60 \mathrm{~m} \times 0.25 \mathrm{~mm}$ i.d., $0.25 \mu \mathrm{m}$ film thickness, J\&W Scientific). Helium was used as a carrier gas at a constant flow of $1.7 \mathrm{ml} / \mathrm{min}$. Extracts were injected on-column and the GC oven was programmed at $40{ }^{\circ} \mathrm{C}$ (4-min hold) to $150{ }^{\circ} \mathrm{C}$ at $10^{\circ} \mathrm{C} / \mathrm{min}, 150-310^{\circ} \mathrm{C}$ at $4{ }^{\circ} \mathrm{C} / \mathrm{min}$, with a final hold time of $75 \mathrm{~min}$.

\section{RESULTS AND DISCUSSION}

To test how commonly rocks are contaminated with anthropogenic hydrocarbon products, we compared the hydrocarbon content detected on rock surfaces with the interior for 26 mostly Proterozoic samples from various drill cores and outcrop locations around the world (Table 2). All of the 26 samples had anthropogenic petroleum products on their exterior surfaces, and 22 also had hydrocarbons derived from polyethylene on their exterior surfaces (the four remaining shales had high natural bitumen contents and polyethylene products were potentially masked). Significantly, in eight of the 22 samples, polyethylene derived hydrocarbons were not limited to the surfaces but had infiltrated the interior of the rock. This clearly indicated that some rocks are permeable to infiltration by anthropogenic hydrocarbons, and that the distinctive polyethylene by-products could potentially be used as a marker to assess whether the interior of a rock had remained sealed from non-indigenous petroleum products.

From the drill cores listed in Table 2, we selected three examples from the Paleoproterozoic McArthur Basin to illustrate the application of plastic contaminants for assessing whether hydrocarbons in the interior of this rock are syngenetic. These three samples were chosen because biomarkers from the McArthur Basin represent the oldest occurrences of a wide range of groups of organisms in the geological record (Summons et al., 1988a; Brocks et al., 2005) and span a range of thermal maturities, from marginally mature to metamorphosed.

The McArthur Basin in northern Australia comprises, from oldest to youngest, the Paleoproterozoic Tawallah, McArthur and Nathan Groups, and the Mesoproterozoic Roper Group. The Wollogorang Formation in the Tawallah Group comprises a sequence of organic-rich black shales with an estimated age of $1.75 \mathrm{Ga}$. However, the Wollogorang Formation was regionally affected by contact metamorphism and, despite high kerogen contents, bitumens have not yet been detected. In contrast, the McArthur Group, with an age of about $1.6 \mathrm{Ga}$, contains arguably the best preserved bitumens of Paleoproterozoic age in the world (Jackson et al., 1986). Dolomitic mudstones of the 1.64-Ga Barney Creek Formation from the southern Glyde River Sub-basin contain well preserved organic matter that can be described as marginally mature with respect to oil generation. Bitumens from the Glyde River have been found to preserve hopanoids and steroids (Summons et al., 1988a), and a large variety of aromatic and aliphatic $\mathrm{C}_{40}$ carotenoid derivatives (Brocks et al., 2005).

\subsection{Example 1: Surficial contamination but syngenetic interior}

Drill core Leila Yard 1 (LY-1) intersects the Barney Creek Formation in the central area of the Batten Trough within the McArthur Basin. This area has generally suffered a more severe thermal history than the southern Glyde River Sub-basin, and kerogen is significantly more mature ( $T_{\max }>470^{\circ} \mathrm{C}$, Crick et al., 1988). However, despite the thermal maturity of the organic matter, preliminary analyses of sedimentary rocks from several drill cores from this area yielded hydrocarbons with apparently low thermal maturities (drill cores LY-1, MY-5, McA-10, CA-2, data not shown; see Jackson et al., 1988, for drill hole locations).

To test whether drill core LY-1 was overprinted by a less mature petroleum product during drilling or storage, we compared the biomarker distribution on the exterior surfaces of mudstone B03288 (LY-1, $403.6 \mathrm{~m}$ ) with those extracted from the interior (Fig. 1). This type of 'interior/ exterior experiment' is described in the experimental section. Fig. 1 compares the saturated hydrocarbon fraction of the 'exterior' and the 'interior', where 'exterior' refers to the millimeter-thick slices of rock that were removed from all outer surfaces with a diamond wafering saw, and 'interior' to the remaining rock core.

The saturated hydrocarbon fraction of the exterior surface extract has an $n$-alkane envelop ranging from $n-\mathrm{C}_{14}$ to $n-\mathrm{C}_{34}$ and includes abundant hopanes. The most intense signals in the $m / z 127$ selected ion chromatogram (Fig. 1A) belong to 5,5-diethylalkanes (5,5-DEAs). In contrast, the interior extract is almost devoid of saturated hydrocarbons, and the $m / z 127$ trace is dominated by vial septa bleed 
Table 2

Presence $(\sqrt{ })$ and absence $(-)$ of anthropogenic hydrocarbons on and in Precambrian rock samples

\begin{tabular}{|c|c|c|c|c|c|c|c|c|}
\hline Group/formation & $\begin{array}{l}\text { Drill core } \\
\text { or outcrop }\end{array}$ & Depth (m) & Origin & Era & $\begin{array}{l}\text { BAQCs } \\
\text { exterior }\end{array}$ & $\begin{array}{l}\text { BAQCs } \\
\text { interior }\end{array}$ & $\begin{array}{l}\text { Petroleum } \\
\text { contamination }^{\mathrm{a}}\end{array}$ & References $^{\mathrm{b}}$ \\
\hline \multirow{10}{*}{$\begin{array}{l}\text { Doushantuo Fm. } \\
\text { (northern China) } \\
\text { Pertatataka Fm. } \\
\text { Pertatataka Fm. } \\
\text { Chuar Group } \\
\text { Nonesuch Shale }\end{array}$} & Mine & - & China & Neoprot. & $\sqrt{ }$ & - & $\sqrt{ }$ & - \\
\hline & Outcrop & Diamictite & China & Neoprot. & $\sqrt{ }$ & - & $\sqrt{ }$ & \\
\hline & BR05-DD01 & 481.85 & Australia & Neoprot. & - & - & $\sqrt{ }$ & - \\
\hline & BR05-DD01 & 483.60 & Australia & Neoprot. & $\sqrt{ }$ & $\sqrt{ }$ & $\sqrt{ }$ & - \\
\hline & outcrop & Grand Canon & USA & Neoprot. & - & - & $\sqrt{ }$ & Summons et al. (1988b) \\
\hline & WC9 & Unknown & USA & Mesoprot. & - & - & $\sqrt{ }$ & Pratt et al. (1991) \\
\hline & WBP-3 & 237.7 & USA & Mesoprot. & $\sqrt{ }$ & $\sqrt{ }$ & $\sqrt{ }$ & Pratt et al. (1991) \\
\hline & WBP-3 & 290.2 & USA & Mesoprot. & $\sqrt{ }$ & - & $\sqrt{ }$ & Pratt et al. (1991) \\
\hline & WBP-4 & 140.7 & USA & Mesoprot. & $\sqrt{ }$ & - & $\sqrt{ }$ & Pratt et al. (1991) \\
\hline & PI-1 & 84.4 & USA & Mesoprot. & $\sqrt{ }$ & - & $\sqrt{ }$ & Pratt et al. (1991) \\
\hline \multirow[t]{2}{*}{ Belt Supergroup } & SC-93 & 494.1 & USA & Mesoprot. & $\sqrt{ }$ & - & $\sqrt{ }$ & - \\
\hline & M-16 & 420.9 & USA & Mesoprot. & $\sqrt{ }$ & - & $\sqrt{ }$ & - \\
\hline \multirow[t]{9}{*}{ McArthur Group } & GR-7 & 45.35 & Australia & Paleoprot. & $\sqrt{ }$ & $\sqrt{ }$ & $\sqrt{ }$ & Summons et al. (1988a) \\
\hline & GR-7 & 287.69 & Australia & Paleoprot. & - & - & $\sqrt{ }$ & Summons et al. (1988a) \\
\hline & GR-7 & 516.65 & Australia & Paleoprot. & $\sqrt{ }$ & - & $\sqrt{ }$ & Summons et al. (1988a) \\
\hline & GR-7 & 683.54 & Australia & Paleoprot. & $\sqrt{ }$ & - & $\sqrt{ }$ & Summons et al. (1988a) \\
\hline & GR-7 & 869.6 & Australia & Paleoprot. & $\sqrt{ }$ & - & $\sqrt{ }$ & Summons et al. (1988a) \\
\hline & GR-10 & 252.05 & Australia & Paleoprot. & $\sqrt{ }$ & - & $\sqrt{ }$ & Summons et al. (1988a) \\
\hline & LY-1 & 403.54 & Australia & Paleoprot. & $\sqrt{ }$ & - & $\sqrt{ }$ & - \\
\hline & McA-5 & 361.63 & Australia & Paleoprot. & $\sqrt{ }$ & - & $\sqrt{ }$ & - \\
\hline & HYC & Mine & Australia & Paleoprot. & $\sqrt{ }$ & $\sqrt{ }$ & $\sqrt{ }$ & Logan et al. (2001) \\
\hline Tawallah Group & $\mathrm{HC}-1$ & 318.64 & Australia & Paleoprot. & $\sqrt{ }$ & $\sqrt{ }$ & $\sqrt{ }$ & - \\
\hline Rove Fm. & 89-mc-1 & $\sim 200$ & USA & Paleoprot. & $\sqrt{ }$ & - & $\sqrt{ }$ & - \\
\hline Dwyka Tillite & GKP-1 & 177.03 & South Africa & Permian & $\sqrt{ }$ & $\sqrt{ }$ & $\sqrt{ }$ & Sherman et al. (2007) \\
\hline Boomplaas Fm. & GKP-1 & 1266.44 & South Africa & Archean & $\sqrt{ }$ & $\sqrt{ }$ & $\sqrt{ }$ & Sherman et al. (2007) \\
\hline Transvaal Supergr. & BH1 Sacha 1 & 2976 & South Africa & Archean & $\sqrt{ }$ & $\sqrt{ }$ & $\sqrt{ }$ & - \\
\hline
\end{tabular}

(Fig. 1B). Some $n$-alkanes, and pristane and phytane are detectable within the interior, but the signals are two orders of magnitude lower than in the exterior and close to detection limits (Table 3). In contrast to the saturated hydrocarbon fraction, the composition and absolute abundance (per gram of rock) of aromatic hydrocarbons were very similar in the interior and exterior extracts (Table 3 and Fig. 2). The dominant compounds were phenanthrene, methylphenanthrenes, dimethylphenanthrenes, pyrene, methylpyrenes, dimethylpyrenes, benzofluoranthene, benzopyrenes and higher polyaromatic hydrocarbons (PAH) up to coronene. Similar distributions and concentrations of highmolecular weight PAH were also observed in the polar fractions of interior and exterior extracts (Fig. 3). The only significant difference between aromatics in these extracts were several unidentified compounds characterized by a prominent $m / z 236$ fragment that were only found in the exterior.

The polar fraction of the interior extract contained palmitic $\left(\mathrm{C}_{16}\right)$ and stearic $\left(\mathrm{C}_{18}\right)$ fatty acids (FA), di(2-ethylhexyl)phthalate and cholesterol (Fig. 3B). To determine whether these compounds were introduced during laboratory procedures, we computed 'extract/blank ratios' (E/ $B) . E / B$ is the concentration of individual compounds in the interior relative to the laboratory system blank, and values $<20$ are conservatively regarded as indicators for background contamination (Brocks et al., 2003a). For the above compounds we measured $E / B\left(\mathrm{C}_{16} \mathrm{FA}\right)=0.9, E / B\left(\mathrm{C}_{18}\right.$ $\mathrm{FA})=1.2, E / B(\operatorname{di}($ 2-ethylhexyl $)$ phthalate $)=1.3$ and $E / B$
$($ cholesterol $)=2.2$. The very low $E / B$ values indicate that these compounds were largely derived from analytical processes in the laboratory. Cholesterol, and to a lesser extent fatty acids, are easily introduced into samples by inadvertent contact with the analyst's fingers (Grenacher and Guerin, 1994). As di(2-ethylhexyl)phthalate is one of the most commonly used plasticizers, it is pervasively found in polar fractions of rock extracts and system blanks. As expected, the four contaminants detected in the laboratory system blank and interior extract $\left(\mathrm{C}_{16}\right.$ and $\mathrm{C}_{18} \mathrm{FAs}$, di(2ethylhexyl)phthalate and cholesterol) are also found in the polar fraction of the exterior extract. However, the extract of the exterior contained various additional compounds not detected in the interior extract. In particular, fatty acid amides (FAA) ranging from $\mathrm{C}_{8}$ to $\mathrm{C}_{18}$ were observed, which is consistent with contamination derived from polyethylene plastic (Grosjean and Logan, 2007). The distribution of FAA is dominated by 9-octadecenamide or oleamide, a common slip agent used in polymers to reduce their friction coefficient and make plastic films easier to handle (Newton, 1993). Due to the relatively low reactivity of amides towards the derivatising agent BSTFA (Blau and King, 1978), oleamide occurs in both the silylated and underivatised forms (Fig. 3A). Besides FAA, numerous other compounds occur in the exterior polar fraction, but not in the interior of the core, and are interpreted as contaminants. These include a series of unknown compounds eluting just before $\mathrm{C}_{12}$ FAA and showing a molecular ion at $\mathrm{m} / \mathrm{z} 292$, a 
Table 3

Bulk characteristics and biomarker data

\begin{tabular}{|c|c|c|c|c|c|c|c|c|c|}
\hline & \multicolumn{3}{|c|}{ LY-1/B03288 } & \multicolumn{2}{|c|}{ HC-1/B03323 } & \multirow{2}{*}{\multicolumn{4}{|c|}{$\begin{array}{l}\text { GR-7/B03162 } \\
\text { Slice }\end{array}$}} \\
\hline & \multirow[t]{2}{*}{ Exterior } & & \multirow[t]{2}{*}{ Interior } & \multirow[t]{2}{*}{ Exterior } & \multirow[t]{2}{*}{ Interior } & & & & \\
\hline & & & & & & A & $\mathrm{C}$ & $\mathrm{E}$ & $\mathrm{G}$ \\
\hline Age of core & & 1981 & & & & & & & \\
\hline Storage in $\mathrm{PE}^{\mathrm{a}}$ (months) & & 6 & & & & & & & \\
\hline TOC $(\%)$ & & 1.2 & & & & & & & \\
\hline$T_{\max }\left({ }^{\circ} \mathrm{C}\right)^{\mathrm{b}}$ & & $>500$ & & & & & & & \\
\hline 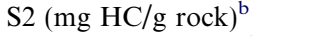 & & 0.06 & & & & & & & \\
\hline $\mathrm{HI}\left(\mathrm{mg} \mathrm{HC} / \mathrm{g}\right.$ TOC) ${ }^{\mathrm{b}}$ & & 5 & & & & & & & \\
\hline Conc. $n-\mathrm{C}_{18}(\mu \mathrm{g} / \mathrm{g})^{\mathrm{c}}$ & 0.28 & & 0.002 & 0.70 & 0.19 & 1.2 & 1.6 & 1.7 & 1.5 \\
\hline Conc. Phen $+\mathrm{MP}(\mu \mathrm{g} / \mathrm{g})^{\mathrm{c}}$ & 0.33 & & 0.26 & 3.34 & 6.33 & 0.077 & 0.033 & 0.012 & 0.015 \\
\hline $\mathrm{Pr} / \mathrm{Ph}$ & 1.5 & & 1.1 & 1.6 & 2.0 & 0.58 & 0.58 & 0.57 & 0.66 \\
\hline $\mathrm{Pr} / n-\mathrm{C}_{17}$ & 0.16 & & 0.53 & 0.37 & 0.54 & 0.79 & 0.71 & 0.67 & 0.78 \\
\hline $\mathrm{Ph} / n-\mathrm{C}_{18}$ & 0.11 & & 0.45 & 0.28 & 0.51 & 1.4 & 1.2 & 1.2 & 1.3 \\
\hline $\mathrm{CP}-\mathrm{CPI}^{\mathrm{f}}$ & 11 & & n.d. & 5.6 & 14 & 1.8 & 1.2 & 1.1 & 1.5 \\
\hline Phen/MP & 0.58 & & 0.48 & 1.0 & 0.84 & 1.6 & 1.7 & 0.59 & 0.72 \\
\hline $\mathrm{MPDF}^{\mathrm{g}}$ & 0.72 & & 0.71 & 0.67 & 0.68 & 0.50 & 0.44 & 0.37 & 0.38 \\
\hline MPI-1 ${ }^{\mathrm{h}}$ & 1.3 & & 1.4 & 0.73 & 0.87 & 0.35 & 0.29 & 0.45 & 0.43 \\
\hline$R_{\mathrm{c}}(\mathrm{MPI}-1)^{\mathrm{i}}(\%)$ & 1.1 & & 1.2 & 0.73 & 0.83 & $2.8^{\mathrm{j}}$ & $2.8^{\mathrm{j}}$ & 0.53 & 0.52 \\
\hline$R_{\mathrm{c}}(\mathrm{MPDF})^{\mathrm{k}}(\%)$ & 1.5 & & 1.4 & 1.3 & 1.3 & 0.94 & 0.82 & 0.65 & 0.68 \\
\hline
\end{tabular}

a Polyethylene.

b ROCK EVAL ${ }^{\odot}$ parameters.

c Concentrations refer to micrograms hydrocarbons per gram of rock. The concentration of octadecane and the combined concentrations of phenanthrene (Phen) and methylphenanthrenes (MP) are guides for relative extract yields of the aromatic and saturated hydrocarbon fractions of exterior and interior extracts. The determination of gravimetric extract yields was avoided to minimize loss of low molecular weight components.

d 'BAQC ratio' $\mathrm{BAQCR}{ }_{19}=\mathrm{C}_{19}-5,5-\mathrm{DEA} / n-\mathrm{C}_{18} * 100 ; \mathrm{C}_{19}-5,5$-DEA $=5,5$-diethylpentadecane. Concentrations were measured as uncorrected signal areas in the $m / z 127$ trace.

e Compounds not detectable.

${ }^{\mathrm{f}}$ Cyclopentane-Carbon Preference Index $(\mathrm{CP}-\mathrm{CPI})=2 *\left(\mathrm{C}_{16}+\mathrm{C}_{18}+\mathrm{C}_{20}+\mathrm{C}_{22}\right) /\left(\mathrm{C}_{15}+2 *\left(\mathrm{C}_{17}+\mathrm{C}_{19}+\mathrm{C}_{21}\right)+\mathrm{C}_{23}\right)$. Concentrations were measured as uncorrected signal areas in the $m / z 68$ trace.

g Methylphenanthrene Distribution Fraction $(\mathrm{MPDF})=(3-\mathrm{MP}+2-\mathrm{MP}) /(3-\mathrm{MP}+2-\mathrm{MP}+9-\mathrm{MP}+1-\mathrm{MP})(\mathrm{MP}=\mathrm{methylphenanthrene})$ (Kvalheim et al., 1987). MP, methylphenanthrene.

${ }^{\mathrm{h}}$ Methylphenanthrene Index (MPI-1) = 1.5*(2-MP + 3-MP)/(Phen + 1-MP + 9-MP) (Radke and Welte, 1983). Phen, phenanthrene. The concentrations of Phen and MP were determined using corrected mass spectral signal areas of the molecular ions.

${ }^{\mathrm{i}}$ Computed vitrinite reflectance equivalent $R_{\mathrm{c}}(\mathrm{MPI}-1)=0.7 * \mathrm{MPI}-1+0.22$ for Phen/MP $<1$, and $R_{\mathrm{c}}(\mathrm{MPI}-1)=-0.55 * \mathrm{MPI}-1+3.0$ for Phen/MP $>1$ (Boreham et al., 1988). Phen/MP $>1$ indicates an inverted Methylphenanthrene Index at very high maturities (Brocks et al., 2003a).

${ }^{\mathrm{j}}$ The large discrepancy between $R_{\mathrm{c}}$ (MPI-1) and $R_{\mathrm{c}}$ (MPDF) suggests that the Phen and MP distributions do not reflect thermal maturity, and this is probably caused by a contamination source that contributed relatively high concentrations of Phen (see also Section 3.3 ).

${ }^{\mathrm{k}}$ Computed vitrinite reflectance equivalent $R_{\mathrm{c}}(\mathrm{MPDF})=-0.166+2.2424 * \mathrm{MPDF}$.

wide range of phthalates and an unknown compound characterized by a dominant molecular ion $\mathrm{m} / \mathrm{z} 410$ (not squalene) (Fig. 3A).

The presence of BAQCs and FAA in the extract of the exterior surface of the core demonstrates that the outer surfaces were contaminated by polyethylene, probably from the plastic bag in which the rock was stored. However, BAQCs and FAA were not detected in the interior extract, suggesting that the rock was largely sealed against penetration by polar and apolar $\mathrm{C}_{17+}$ products. Similarly, saturated hydrocarbons with a typical petroleum composition were found in high abundance on the exterior surfaces compared to their near absence in the interior extract. This strongly suggests that the saturated hydrocarbons on the surfaces are contamination. The traces of low molecular weight $n$-alkanes and acyclic isoprenoids found in the inside
(Fig. 1B) may either represent the residue of a thermally mature indigenous bitumen or, more likely, a small fraction $(<1 \%)$ of surficial contamination that was not removed by trimming of rock surfaces. Therefore, neither the saturated hydrocarbons in the exterior nor in the interior are interpreted as indigenous.

By excluding the exterior surficial contaminants, the interior extract almost exclusively yielded aromatic hydrocarbons. Bitumens that lack saturated hydrocarbons are indicative of sedimentary organic matter that has matured to the gas condensate or dry gas stages (Brocks et al., 2003a), and this appears to be consistent with the thermal maturity of kerogen in drill core Leila Yard-1 ( $T_{\max }>500{ }^{\circ} \mathrm{C}$; Table 3 ). Therefore, the apparent consistency of the thermal history of the host rock and the thermal maturity of extractable bitumen, and the similar 


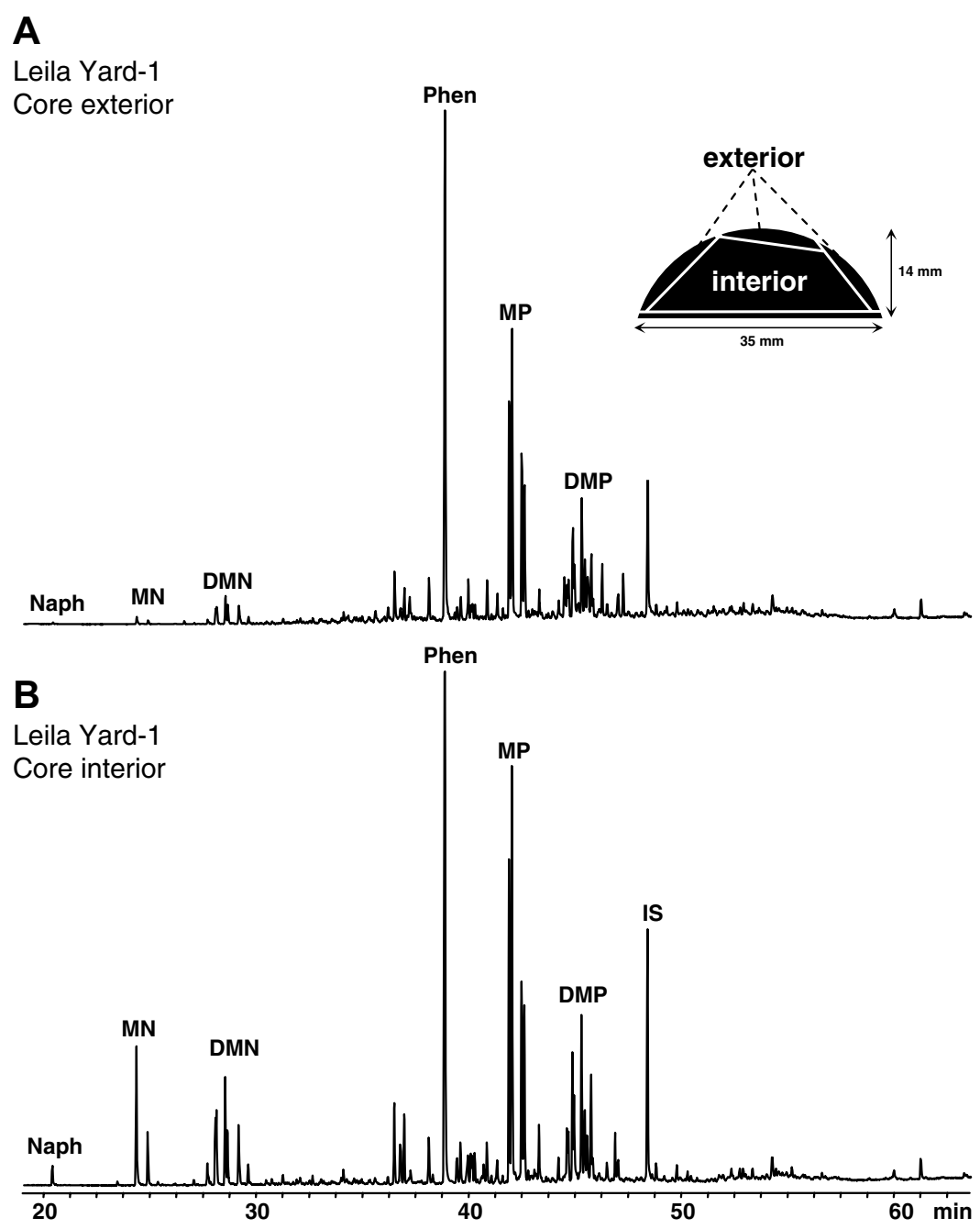

Fig. 2. Sum of selected ion chromatograms $m / z$ 119, 128, 133, 134, 142, 156, 173, 178, 184, 192, 198, 206, 231, 244, 245, 253, 259, 267 and 273 of the aromatic hydrocarbon fraction of sample B03288 (drill core LY-1, $403.54 \mathrm{~m}$, Barney Creek Formation, McArthur Basin). (A) Exterior extract, and (B) interior extract. Naph, naphthalene; MN, methylnaphthalene; DMN, dimethylnaphthalene; Phen, phenanthrene; MP, methylphenanthrene; DMP, dimethylphenanthrene; IS, internal standard $d_{14}$-para-terphenyl.

concentration and distribution of aromatic hydrocarbons in the interior compared to the exterior (Table 3 and Fig. 2) suggest that the aromatic compounds within the core are syngenetic.

The results of this interior/exterior experiment demonstrate that the analysis of extracts without prior removal of contaminated exterior surfaces results in misleading interpretations about the presence, distribution and maturity of hydrocarbons. Despite a severe thermal history, this shale would appear to contain comparatively immature bitumen and preserved hopanes if the exterior surfaces were not removed before the analysis. In contrast, extraction of the interior of the core recovers a pyrolytic bitumen with a composition that is consistent with the history of the rock. Therefore, it is possible to recover a syngenetic hydrocarbon signal by exclusion of exterior rock surfaces.

The following examples will show that anthropogenic hydrocarbon contaminants can infiltrate the interior of even well consolidated rock, and that trimming and discarding outer surfaces may still lead to misleading results.

\subsection{Example 2: Surficial and internal contamination}

The Wollogorang Formation near the top of the Tawallah Group is a 100 - to $150 \mathrm{~m}$ thick sequence of red siltstone, dolostone, coarse grained dolomitic sandstone and black, organic-rich shale with an estimated age of $\sim 1.75 \mathrm{Ga}$. The Wollogorang Formation largely escaped deep regional burial but suffered extensive contact metamorphism by intrusive phases of the Gold Creek Volcanics (Donnelly and Jackson, 1988). Diamond drill core Heifer Creek-1 (HC-1) intersects the Wollogorang Formation in the southeastern margin of the basin where the black shale facies has a distance of up to $\sim 60 \mathrm{~m}$ from the intrusions and is least affected by contact metamorphism. To search for syngenetic hydrocarbons in this core, we conducted an interior/ exterior experiment on a fissile black shale (B03323, HC$1,318.64 \mathrm{~m})$.

The extract yields $(<100 \mathrm{ppm})$ and distributions of saturated and aromatic hydrocarbons in interior and exterior extracts were broadly similar (Table 3 and Fig. 4). The 

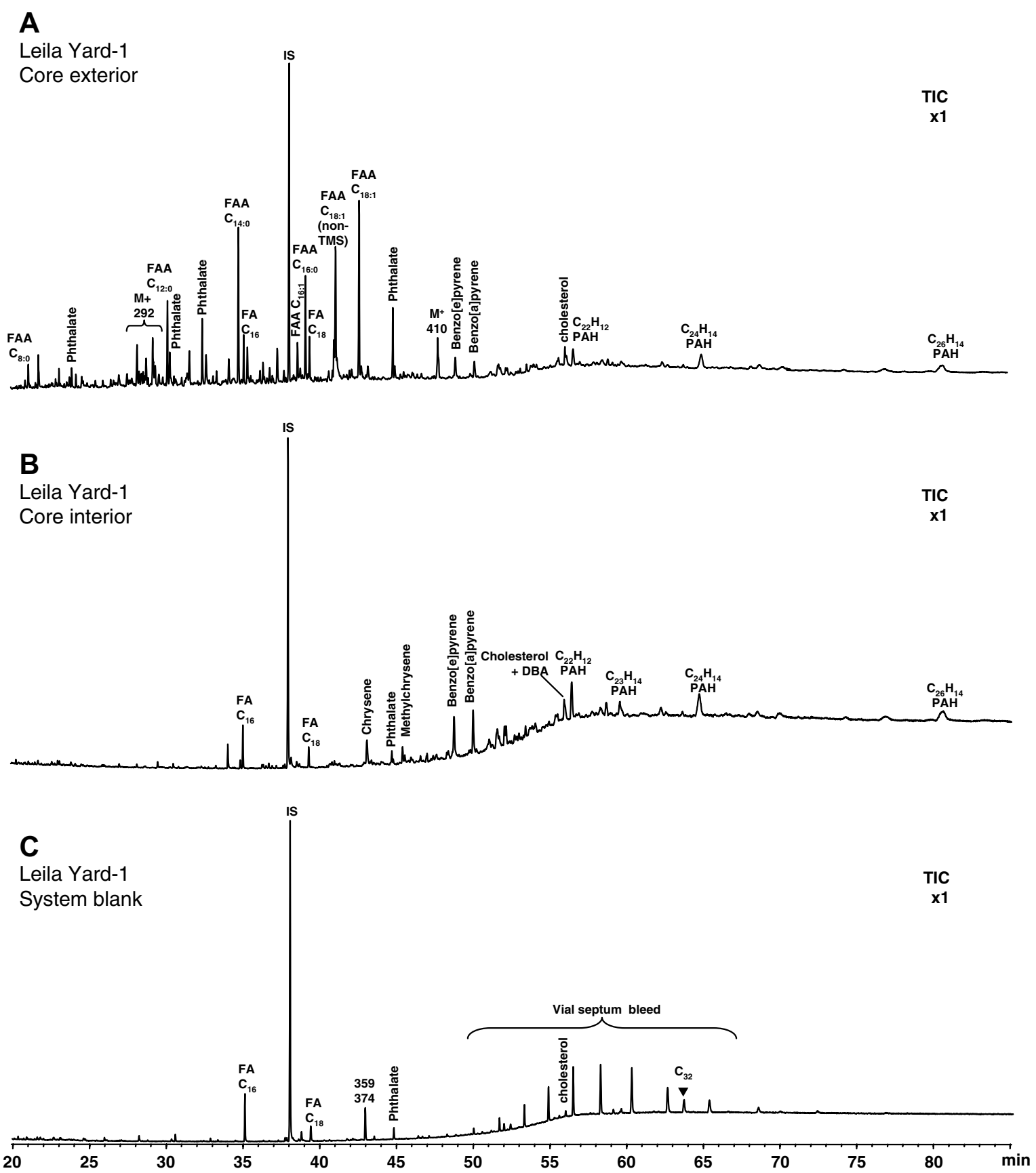

Fig. 3. Total ion chromatograms (TIC) of the silylated polar fraction of sample B03288 (drill core LY-1, 403.54 m, Barney Creek Formation, McArthur Basin). The chromatograms are scaled relative to extract yields and signal heights in the three panels can be directly compared. (A) Exterior portion of the drill core, (B) interior, and (C) system blank. IS, internal standard; FAA, fatty acid amide; FA, fatty acid; DBA, dibenzo[ $a, h]$ anthracene; PAH, polycyclic aromatic hydrocarbon; $\mathbf{\nabla}, n$-alkan-1-ol. Unidentified compounds are described by their main mass fragment ions.

extract from the exterior surface of the drill core contained abundant BAQCs (Fig. 4A). This is not unexpected, as B03323 was stored in a polyethylene plastic bag. Surprisingly, BAQC concentrations (per gram of rock) were even higher in the interior of the core compared to the exterior surfaces (Table 3 and Fig. 4B). To express these different degrees of BAQC contamination, we computed the abundance of 5,5-diethylpentadecane $\left(\mathrm{C}_{19}-5,5\right.$-DEA $)$ relative to $n$-octadecane $\left(n-\mathrm{C}_{18}\right)$. The relative concentration was then expressed in percent as the 'BAQC ratio' $\left(\mathrm{BAQCR}_{19}=\right.$ $\mathrm{C}_{19}-5,5-\mathrm{DEA} / n-\mathrm{C}_{18} * 100$; concentrations were measured as uncorrected signal areas in the $m / z 127$ trace). For the exterior extract of $\mathrm{HC}-1, \quad \mathrm{BAQCR}_{19}=67 \%$, while $\mathrm{BAQCR}_{19}=370 \%$ for the interior, more than five times higher (Fig. 4). Other differences between hydrocarbons extracted from the interior and exterior of the rock are higher 


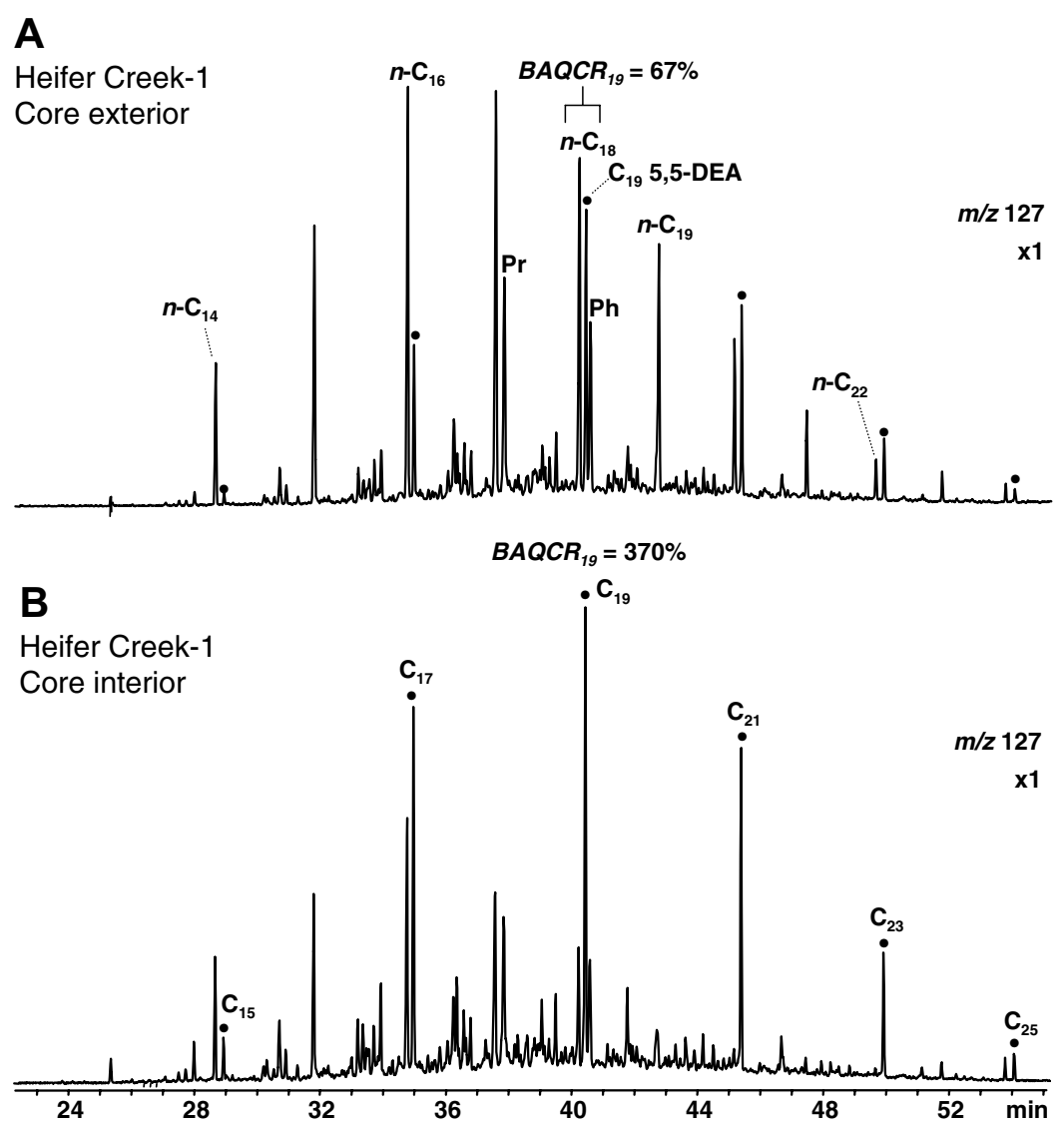

Fig. 4. Partial mass chromatogram $\mathrm{m} / z 127$ of the saturated hydrocarbon fraction of sample B03323 (drill core HC-1, 318.64 m; Wollogorang Fm., Tawallah Group, McArthur Basin). (A) Exterior of the core, (B) interior. Signal heights are scaled to extract yields per gram of rock. -, 5,5-DEA series; $\mathrm{Pr}$, pristane; $\mathrm{Ph}$, phytane.

pristane/heptadecane and phytane/octadecane ratios in the interior (Table 3), and a more rapid decrease of $n$-alkanes with increasing molecular mass (Fig. 4).

As observed for saturated and aromatic hydrocarbons, polar compounds show similar distributions in the interior and exterior extracts (Fig. 5). Among the main compounds are palmitic and stearic acids which are the most common FA derived from animal and vegetable fats and are commonly used as lubricants and as additives to industrial preparations. Shorter chain FA in the range $\mathrm{C}_{10}-\mathrm{C}_{14}$ are also observed in both the exterior and interior polar fractions. Other contaminants include cholesterol, phthalates and an unidentified compound characterized by a preponderant molecular ion $\mathrm{m} / z 410$ (Fig. 5) mentioned earlier among contaminants of the outside polar fraction of Leila Yard-1 sample B03288 (see Section 3.1). The dominant compound IIa (Table 4) has a molecular ion $\mathrm{m} / \mathrm{z} 234$ and a major fragment $\mathrm{m} / \mathrm{z} 219$ and is identified as 3,5-di-tert-butyl-4-hydroxybenzaldehyde (BHT-CHO). BHT-CHO appears as an underivatised parent compound in the mass chromatogram, as silylation is inhibited by the steric hindrance of the tert-butyl groups in ortho positions of the hydroxyl group. BHT-CHO is a degradation product of butylated hydroxytoluene (BHT) (Mikami et al., 1979; Fries and Püttmann, 2002), a com- mon antioxidant used in a wide range of products including petroleum-based lubricants and plastics (Grosjean and Logan, 2007). Two isomers of the silylated derivative of

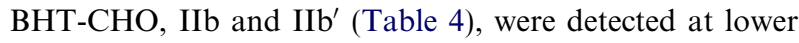
relative abundances (Fig. 5). Two additional compounds in the polar fractions appear to be related to the degradation of hindered phenolic antioxidants: compound I tentatively identified as 2,6-di-tert-butyl-benzoquinone and compound III as 3,5-di-tert-butyl-4-hydroxybenzoic acid (Table 4). 2,6-Di-tert-butyl-benzoquinone was found among degradation products of polyethylene plastic films containing high molecular weight BHT-based antioxidants Irganox-1010 (pentaerythrityl tetrakis(3-(3',5'-di-tert-butyl4'-hydroxyphenyl)propionate)) and Irgafos-168 (tris(2,4di-tert-butylphenyl)phosphite) and is a common product of oxidation of such hindered phenols (Haider and Karlsson, 2002). 3,5-di-tert-butyl-4-hydroxybenzoic acid arises from the alteration of BHT (Mikami et al., 1979). The occurrence of these BHT-related products in the polar fractions of HC-1 rocks probably results from 6 months of storage in "Seismic Supply Kaltex" polyethylene plastic bags, which have been shown to contain BHT (Grosjean and Logan, 2007). Contact with polyethylene also led to the presence of FAA in both the exterior and interior HC-1 polar fractions (Fig. 5). 


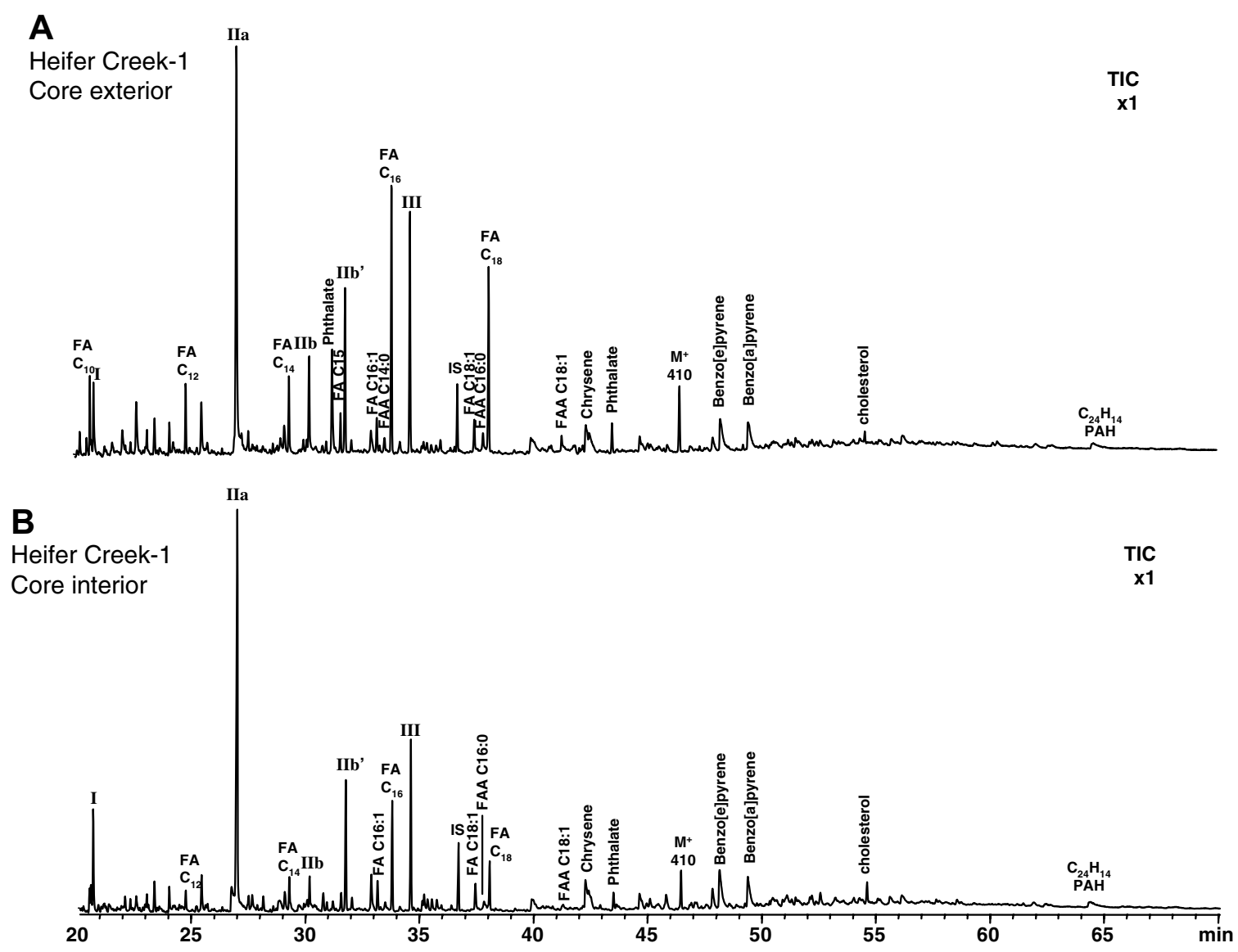

Fig. 5. TICs of the silylated polar fraction of sample B03323 (drill core HC-1, 318.64 m; Wollogorang Fm., Tawallah Group, McArthur Basin). (A) Exterior of the core, (B) interior. IS, internal standard; FAA, fatty acid amide; FA, fatty acid; PAH, polycyclic aromatic hydrocarbons. For identification of structures with roman numerals refer to Table 4. Unidentified compounds are described by their main mass fragment ions.

The presence of BAQCs in the interior of the drill core, even after removal of the outer surfaces, indicates that the rock was extensively infiltrated by anthropogenic hydrocarbon contamination. The high concentration of BAQCs in the interior section probably reflects the fissile nature of the shale with a high number of bedding-parallel cracks that may have served as conduits for surficial contaminants and would have offered a high internal surface area for the adsorption of hydrocarbons. Although BAQCs thoroughly permeated the Wollogorang shale, it is not clear whether the petrogenic hydrocarbons are syngenetic. The similar distribution of petrogenic hydrocarbons in interior and exterior could be interpreted as evidence for an indigenous origin. However, typical characteristics found in most Paleoproterozoic and Mesoproterozoic bitumens, including high ratios of methylalkanes to $n$-alkanes, a significant unresolved complex mixture and a long $n$-alkane 'tail' (e.g. Summons et al., 1988a), are absent in the HC-1 extract. The hydrocarbon distribution seen in Fig. 4A resembles the typical distillation cut of diesel oil (Brocks et al., 2003a). The thermal maturity of the aromatic fraction based on phenanthrene ratios and high concentrations of alkylated PAH relative to parent PAH (Table 3 ) indicates that the hydro- carbons are, at best, mature with respect to oil generation, but not overmature or pyrolytic as would be expected for indigenous hydrocarbon residues (e.g. George, 1992). The described differences between the saturated hydrocarbon distribution in exterior and interior could be explained by diffusion effects during movement of hydrocarbons into the rock (Brocks, 2001).

In summary, the abundance of BAQCs and other plastic contaminants in the interior of the HC-1 shale, the absence of a typical Precambrian biomarker fingerprints and a poor correlation of biomarker maturity and thermal history of the host rock suggest extensive contamination of the exterior and interior of the core with petroleum based saturated and aromatic hydrocarbons. Therefore, the bitumen should not be described as indigenous and the biomarkers cannot be used to make predictions about late Paleoproterozoic ecosystems. Furthermore, this example demonstrates that hydrocarbons can infiltrate fissile shale. Therefore, the removal of rock surfaces prior to analysis does not necessarily remove non-indigenous hydrocarbons. It is important to compare the solvent extracts of both the exterior and interior of rocks and not just discard the exterior surface and assume that contamination is limited to the outside of drill core or outcrop material. 
Table 4

Structures and MS characteristics of several polar contaminants

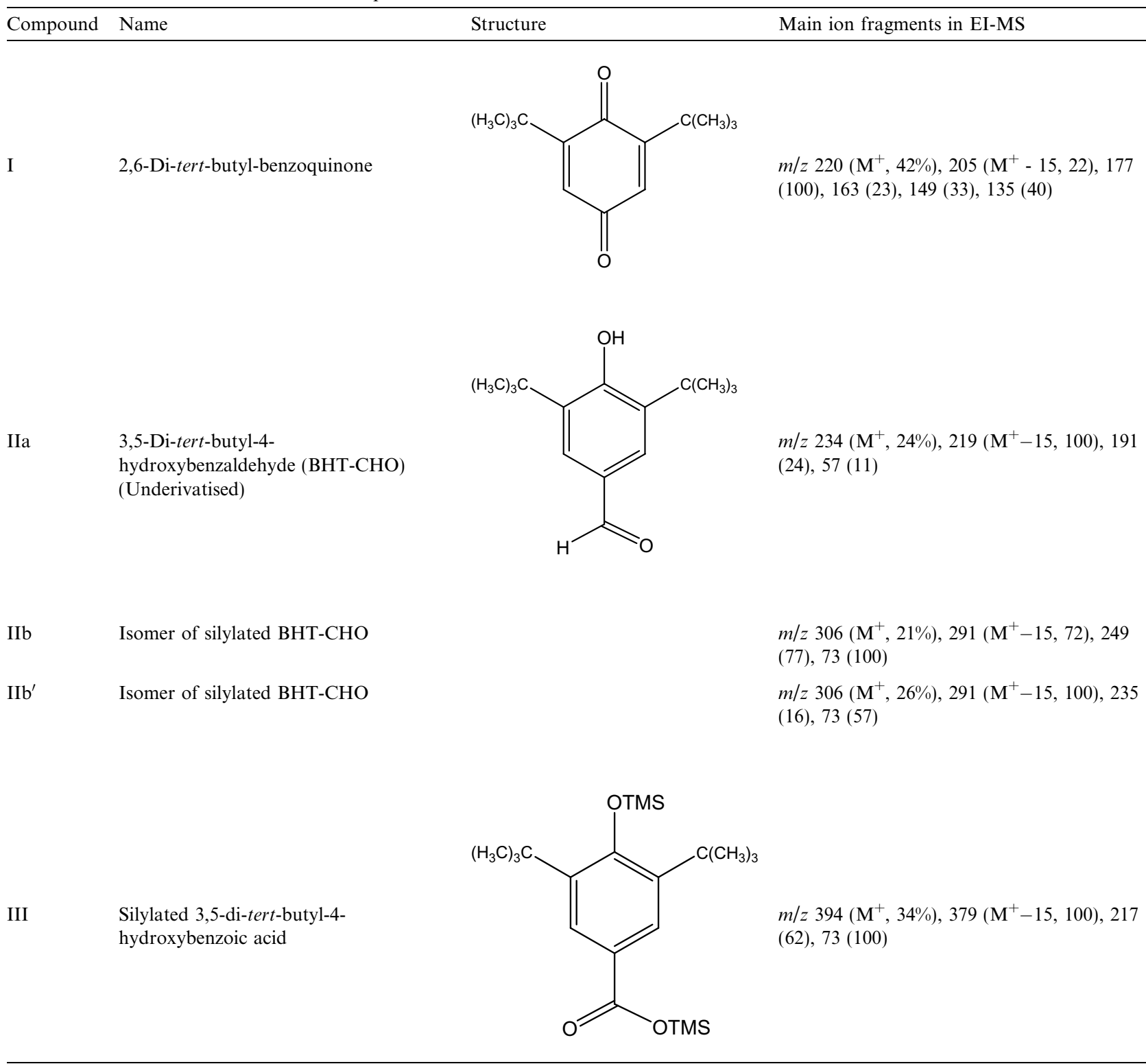

\subsection{Example 3: Recognition of partially contaminated interior}

Sample B03162 from the Barney Creek Formation, McArthur Group, was collected from diamond drill core Glyde River-7 (GR-7) located in the Glyde River Sub-basin. GR-7 is known to contain high concentrations of extractable bitumens and biomarkers (Summons et al., 1988a). To test which biomarkers are indigenous, we performed a 'slice extraction' experiment. In this type of experiment a piece of drill core is sectioned into millimeter-thin wafers parallel to the drilling direction and orthogonal to bedding (Fig. 6A). The first slice (slice A) contains the exterior rounded surface of the drill core and, thus, potential contaminants from drilling, storage and transport. Consecutive slices $\mathrm{B}$ to $\mathrm{F}$ represent material with increasing dis- tances from the surface towards the interior center of the core. Although slice $\mathrm{G}$ comes from the center of the core, it includes a surface that was exposed to potential contaminants after the full core had been cut in half (presumably immediately after drilling). B03162 was collected from drill core in Darwin in 2003 and was then stored in a sealed polyethylene plastic bag for 6 months before analysis.

To test whether the sample was permeable to hydrocarbon contamination, we plotted $\mathrm{BAQCR}_{19}$ for each core slice with increasing distance from the drill core surface (Fig. 7A). This type of plot yields a spatial distribution of polyethylene contaminants in the rock. BAQCs were most abundant on the exterior rounded surface of the core (slice $\mathrm{A}, \mathrm{BAQCR}_{19} \approx 40 \%$ ) and the exterior surface that was cut after drilling (slice G, BAQCR $19 \approx 30 \%$ ). However, 5,5DEAs were also detected in the inside slices $\mathrm{C}$ and $\mathrm{E}$, albeit 


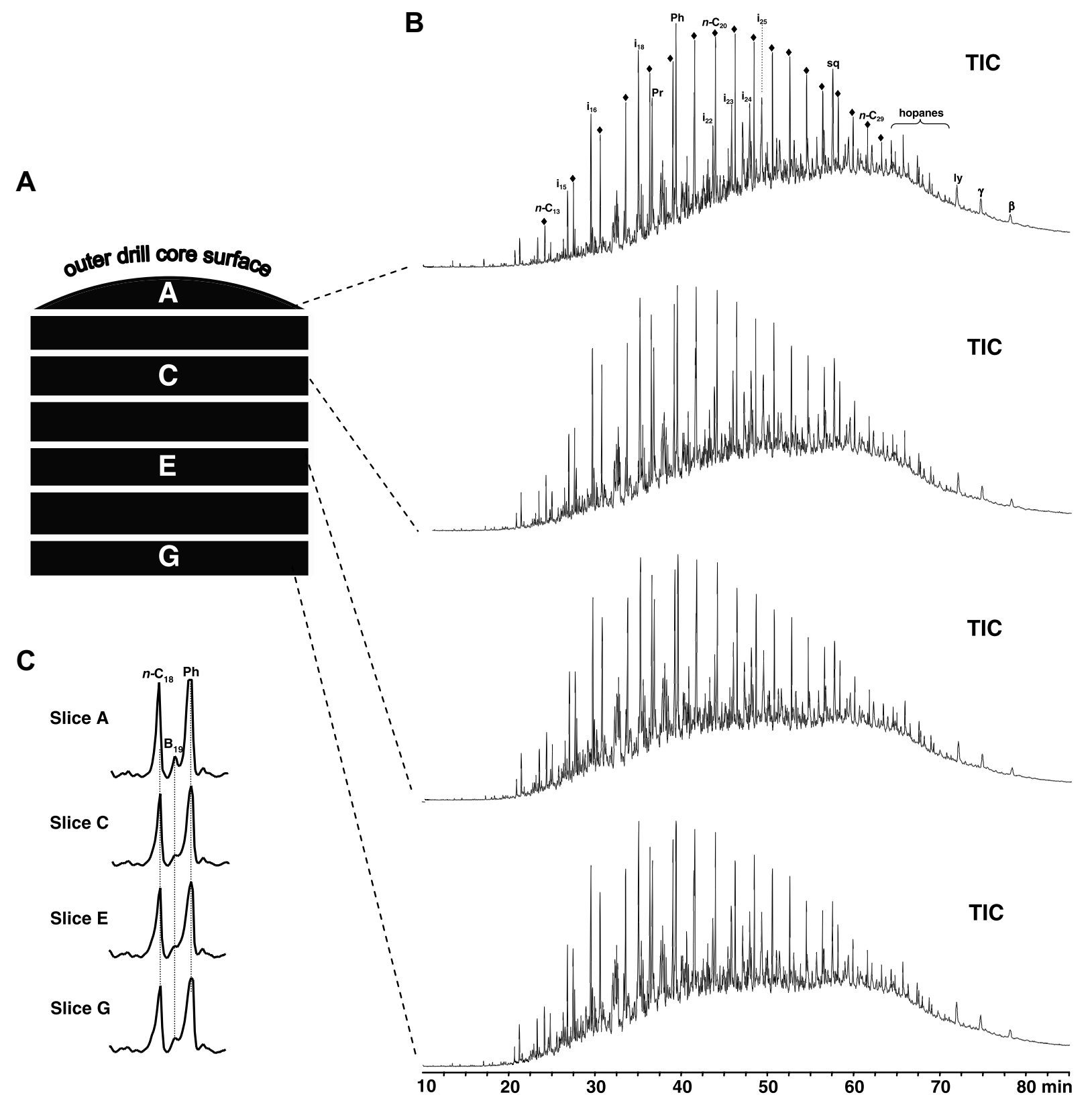

Fig. 6. (A) Cutting diagram of the 'slice-extraction experiment' of drill core sample B03162 (GR-7, $45.35 \mathrm{~m}$ ), (B) full-scan chromatograms of the saturated hydrocarbon fraction of slices $\mathrm{A}-\mathrm{G}$, and $(\mathrm{C})$ magnification of the elution range of $n$-octadecane; $\mathrm{B}_{19}$ indicates $\mathrm{C}_{19} 5,5-\mathrm{DEA}$ BAQC. $\diamond$-alkanes; $i_{x}$, regular acyclic isoprenoids with $x$ carbon atoms; Pr, pristane; Ph, phytane; sq, squalane; ly, lycopane; $\gamma, \gamma$-carotane; $\beta, \beta$-carotane.

in lower concentrations $\left(\mathrm{BAQCR}_{19} \approx 10 \%\right)$. This demonstrates that the core was permeable and the interior susceptible to contamination. Contamination by polyethylene derived hydrocarbons is also evident in $\mathrm{m} / \mathrm{z}=68$ mass chromatograms of exterior and interior slices that show the distribution of alkylcyclopentanes (Fig. 8). The alkylcyclopentane homolog distribution for the exterior slices has a distinct even-over-odd predominance. Even-numbered alkylcyclopentanes are a typical by-product of polyethylene production and these hydrocarbons are commonly found in association with BAQCs. The even number predominance among alkylcyclopentanes can be measured through a 'Cyclopentane-Carbon Preference Index' $\quad\left(\mathrm{CP}-\mathrm{CPI}=2 *\left(\mathrm{C}_{16}+\mathrm{C}_{18}+\mathrm{C}_{20}+\mathrm{C}_{22}\right) /\left[\mathrm{C}_{15}+2 *\right.\right.$ $\left(\mathrm{C}_{17}+\mathrm{C}_{19}+\mathrm{C}_{21}\right)+\mathrm{C}_{23}$. CP-CPI indicates high evenover-odd carbon preference in the exterior slices $A$ and $G$ (Table 3 and Fig. 7B), a distribution clearly related to polyethylene contamination. However, CP-CPI values are low in interior slices $\mathrm{C}$ and $\mathrm{E}$, suggesting that the cyclopentanes in the interior are predominantly indigenous.

Under GC-MS full scan conditions, the observable differences between the saturated hydrocarbon fractions of the four slices appear small (Table 3 and Fig. 6B). The only major differences observed between the aromatic fractions 


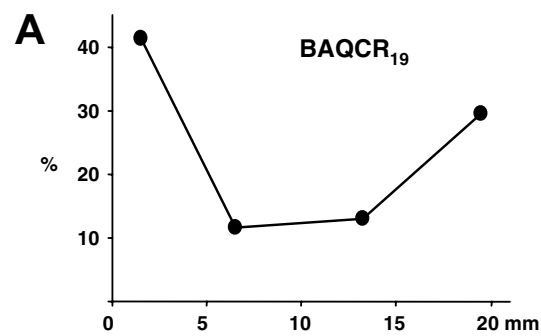

B
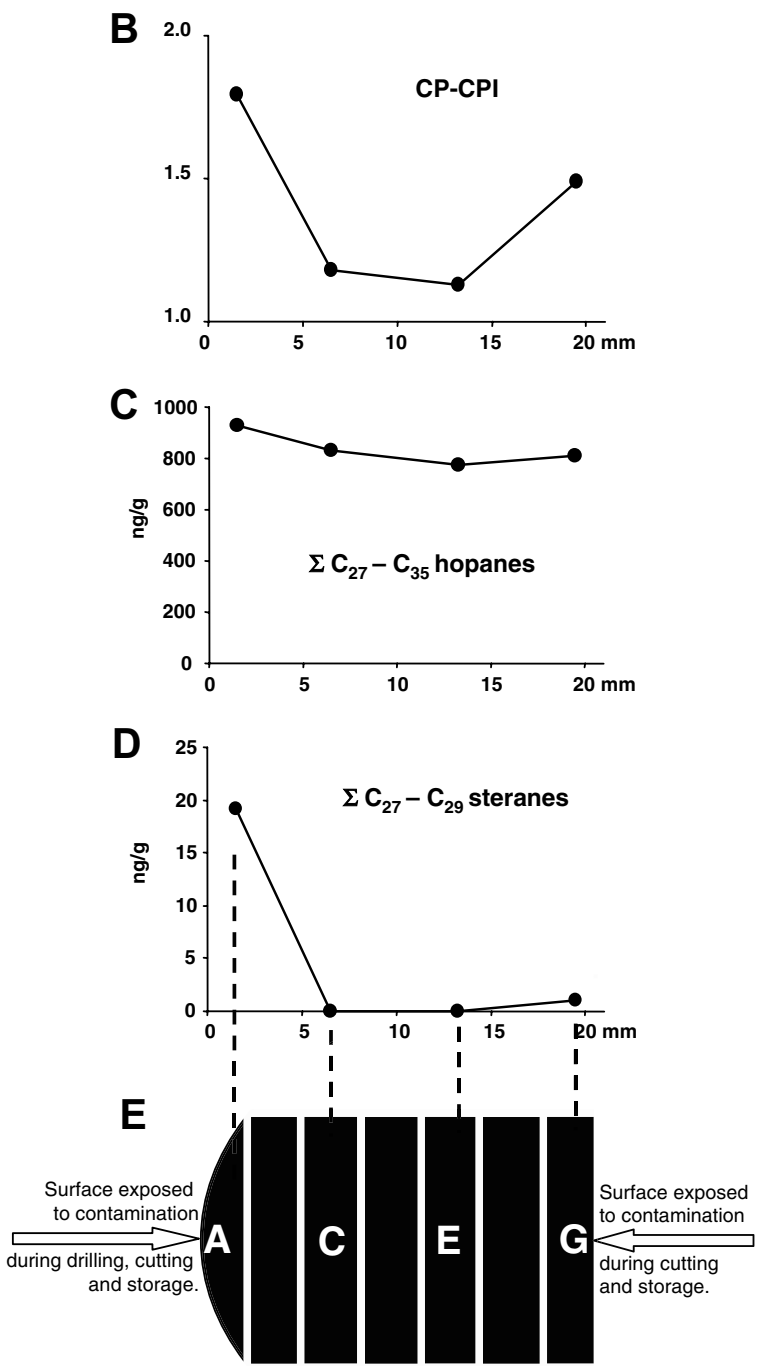

Fig. 7. Biomarker ratios and biomarker concentrations with increasing distance from the rounded drill core surface to the drill core center in the slice extraction experiment on sample B03162 (drill core GR-7, 45.35 m). (A) The relative abundance of BAQCs expressed using $\mathrm{BAQCR}_{19}$ (see text), (B) the even-over-odd predominance of cyclopentanes expressed as CP-CPI (see text), (C) the summed concentration of $\mathrm{C}_{27}$ to $\mathrm{C}_{35}$ hopanes (nanograms per gram of rock determined using uncorrected MRM signal areas relative to the $\mathrm{D}_{4}$ standard), (D) the summed concentration of $\mathrm{C}_{27}$ to $\mathrm{C}_{29}$ steranes, and (E) a diagram of the sectioned drill core.

of interior and exterior slices are significantly elevated concentrations of phenanthrene, 3- and 2-methylphenanthrene, fluoranthene and pyrene in slices $\mathrm{A}$ and $\mathrm{C}$ in comparison to slices $\mathrm{E}$ and $\mathrm{G}$, with a significant effect on measured aro- matic maturity parameters (Table 3 ). An elevation of fluoranthene and pyrene in exterior extracts was also observed in a second drill core from the Northern Territory Geological Survey drill core archive in Darwin, NT, and may be related to drilling additives or exposure to petroleum combustion products.

As discussed above, shales from the Glyde River contain abundant carotenoid and hopane biomarkers. However, the concentration of steranes in whole-rock extracts is extremely low compared to co-occurring hopanoids (Summons et al., 1988a). Thus, to test which biomarkers are indigenous, we examined data from our slice extraction experiment and plotted the concentration profile of hopanes against increasing distance from the exterior rounded surface (Fig. 7C). Although concentrations are slightly elevated on the exposed outer surfaces (slices $A$ and $G$ ) in comparison to the interior (slices $\mathrm{C}$ and $\mathrm{E}$ ), the profile is essentially flat. Therefore, we interpret the hopanes as predominantly indigenous. However, the spatial distribution of steranes in the core is quite different from the hopane profile and more closely resembles the distribution of BAQCs (Fig. 7A and D). Steranes are found in slice A (outer rounded surface) and slice $G$ (surface exposed after cutting), but were below detection limits in the interior (slices $\mathrm{C}$ and $\mathrm{E}$ ), even using selective GC-MS/MS detection techniques. As steranes and hopanes have very similar adsorption and diffusion properties (Carlson and Chamberlain, 1985), the differences in spatial distribution can not be explained by differential redistribution of these two biomarker classes in the rock. Therefore, we conclude that a large proportion of $\mathrm{C}_{27}-\mathrm{C}_{35}$ hopanes are indigenous, but that the $\mathrm{C}_{27}-\mathrm{C}_{29}$ steranes are contamination derived from surface exposure to petroleum products during drilling, handling or storage. Previous reports of low concentrations of steranes in these rocks (Summons et al., 1988a) should now be reassessed.

\subsection{Strategies to test biomarker syngeneity}

Rinsing or trimming of surfaces is commonly regarded as adequate to remove surficial contaminants that may have stained or infiltrated rocks. However, attempts in our laboratory to remove petroleum hydrocarbons from artificially stained rock pieces by ultrasonication in solvents failed. More seriously, the slice extraction experiment in example 3 shows that surficial hydrocarbons can penetrate compact mudstone through microscopic fissures centimeters deep. Nano-fissures may be generated by pressure release during recovery of drill core material from depth or through desiccation, and are present in many geological samples. Example 2 shows that contamination of fissile rock can be so pervasive that contaminant hydrocarbons may have higher concentrations (per gram of rock) in the interior portion of a core compared to material towards the exterior surfaces. This phenomenon may be caused by permeation of an extensive fracture system by hydrocarbons and subsequent evaporation and degradation of contaminants on the outer surfaces. In these cases, even trimming of rock surfaces is insufficient to remove contaminants and will lead to the wrong conclusions. 

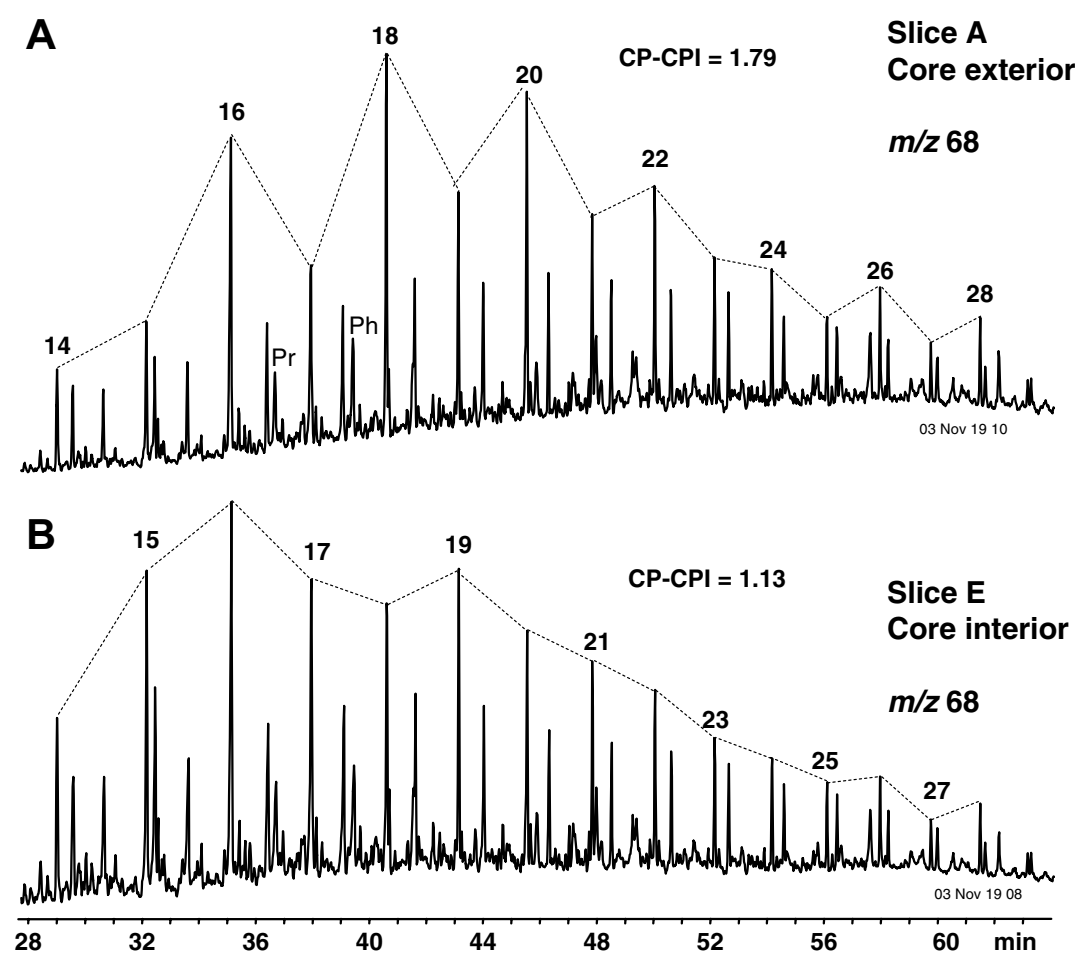

Fig. 8. $\mathrm{m} / \mathrm{z} 68$ selected ion chromatogram showing $\mathrm{C}_{14}-\mathrm{C}_{28}$ alkylcyclopentanes (sample B03162). (A) Exterior slice A, and (B) interior slice $\mathrm{E}$ (compare Fig. 6A). CP-CPI, Cyclopentane-Carbon Preference Index (see text).

The challenge is to recognize whether a particular rock was permeable to hydrocarbons, and to distinguish permeating contaminant hydrocarbons from indigenous biomarkers. Hydrocarbon contamination is not exclusively a problem of organically lean or overmature samples. Even in shales with high extract yields it can be difficult to demonstrate that biomarkers in very low concentrations are indigenous. For instance, the mudstone in example 3 has high bitumen extract yields, and includes hopanes and steranes. However, while the hopanes are indigenous, the traces of steranes are almost certainly later additions, as demonstrated in Section 3.3 (Fig. 7). Therefore, contamination with petroleum products is not only a problem that affects lean and overmature rocks, it can significantly affect the interpretation of biomarkers extracted from organic-rich samples.

In the following section we outline a series of procedures and protocols that may provide greater confidence in the interpretation of biomarkers. We will also explore some of the arguments customarily used to assess syngeneity in light of the results presented in this manuscript.

\subsection{Laboratory system blanks}

System blanks are required to determine the fraction of individual biomarkers in rock or sediment extracts that are derived from laboratory background contamination. In our laboratory, the most significant source of background and cross-contamination is the preparation of rock powder from whole rock. Therefore, we prepare one or two system blanks that consist of combusted rough quartz sand or split quartz pebbles in parallel with each set of five to nine samples. The quartz is crushed to powder using the same procedures and vessels as for the rocks, and the solvent extract of the quartz powder serves as the laboratory system blank which is carried through all fractionation and analytical procedures. System blanks that do not capture the preparation of rock powder are not sufficient to assess laboratory contamination. The influence of laboratory background contamination is monitored using the extract/ blank ratio $(E / B)$, the concentration of individual biomarkers in the rock or sediment extract relative to the corresponding blank (Brocks et al., 2003a). As kerogen may strongly absorb contaminant hydrocarbons (Oehler, 1977), organic-rich samples may attract more laboratory background contamination than the blank consisting of quartz powder. Therefore, Brocks et al. (2003a) interpreted biomarkers with $E / B<20$ as potentially non-indigenous. If extract/blank ratios are close to this limit, then laboratory background contamination may also introduce systematic errors in biomarker ratios. In these cases, we recommend subtracting measured biomarker concentrations in the system blank from the rock extracts.

However, while system blanks are critical to assess the level of contamination occurring during processing of samples in a laboratory, they cannot be used as arguments for syngeneity of biomarkers in rock extracts, simply because they do not capture contamination during collection and storage. The three examples in this manuscript show that the absolute abundances of individual contaminant biomarkers present in rocks before they are analyzed can be orders of magnitudes higher than in the corresponding lab- 
oratory system blanks. Therefore, system blanks alone are not sufficient to make statements about biomarker syngeneity, and it is necessary to quantify hydrocarbon products that stained rocks or sediments during drilling, storage and collection.

\subsection{Recognizing and quantifying contamination in rocks}

The permeability of rocks to hydrocarbons can be tested using BAQCs and other polyethylene by-products. 5,5Diethylalkanes are very common in geological samples and easily detected using $\mathrm{m} / \mathrm{z} 127$ selected ion chromatograms. The different homologous series of BAQCs have similar molecular masses and chemical properties to many petroleum hydrocarbons and, thus, simulate the penetration of rock by petroleum products well. If the rock interior, after removal of all exterior surfaces, tests positive to BAQCs (or other unambiguous contaminants), then the sample has been infiltrated. The ratios BAQCr and $\mathrm{CP}$ CPI of exterior/interior extracts can be used to make quantitative assessments of the degree of infiltration.

If infiltration is observed for polyethylene by-products, a detailed and quantitative comparison of hydrocarbons in the interior and exterior extracts can yield information about whether petroleum products, including biomarkers, have entered the rock. Slight distribution differences between biomarkers in the interior and exterior may be difficult to assess using interior/exterior experiments alone, but distinct concentration differences (such as in example 1) can be used to make clear assignments as to which compounds are contaminants and which may be syngenetic. In ambiguous cases, when a biomarker occurs in low concentrations in the interior extract but in higher concentrations on the exterior, a slice extraction experiment may give information on which compounds penetrated the rock from the outside.

Slice extraction experiments may also help to identify the sources of the biomarkers detected in metamorphosed Archean rocks by Sherman et al. (2007). Sherman et al. (2007) studied the interior and exterior of rocks from two Archean drill cores from South Africa and found that most samples were surficially contaminated with anthropogenic petroleum products. They propose a methodology where indigenous bitumen can be recovered from the interior of rock after removal of the outer $3-5 \mathrm{~mm}$. The hydrocarbons recovered after removal of the surfaces were then interpreted as indigenous Archean biomarkers. The technique proposed by Sherman et al. (2007) assumes that contaminant hydrocarbons could only have penetrated the rock $5 \mathrm{~mm}$ deep and no deeper. However, this contradicts our observation that contaminants can pervade the entire cross section of drill core. The case for an Archean age of the biomarkers is also weakened by the fact that the hydrocarbon content of the interior of the core was an order of magnitude lower than in the exterior 3-5 mm (Fig. 4 in Sherman et al., 2007), and that extract/blank ratios were as low as 4. Sherman et al. (2007) suggest another methodology to recover indigenous bitumens from Archean rocks that we do not recommend. Of 70 extracts from two Archean drill cores, 37 were selectively removed from the study because they displayed biomarker distributions that were deemed to have 'characteristics (that) are not typical of Archean bitumens', for instance biomarker ratios indicating low thermal maturity. By default, the remaining 33 bitumens all displayed high apparent maturities, and these were then inferred to be indigenous to the Archean rocks. Given our evidence showing how easily rock samples can be pervasively infiltrated by contamination, these results should be treated with great caution. Furthermore, Sherman et al. (2007) also suggests that covariation of biomarker patterns with facies are strong evidence for biomarker syngeneity. However, as we shall discuss in the next section, this is not always the case.

\subsection{Covariation of biomarker patterns}

Intuitively, contamination by drilling fluids or during storage in plastic containers should affect all samples equally that originated from a single drill core and were collected together. According to this view, contamination should be characterized by a consistent hydrocarbon pattern and relatively stable concentrations independent of lithology or depositional environment. Therefore, biomarker concentrations and biomarker ratios that show covariation with lithology, extract yields or TOC in a sedimentary sequence have been proposed as evidence for syngeneity (Brocks et al., 1999). However, the selective occurrence of polyethylene by-products in particular lithologies challenges this concept. A study of the distribution of BAQCs in rocks and sediments aged from the Paleoproterozoic to the present suggests that the compound class is often associated with sediments that contain dysoxic benthic microbial mats, but not with sediments deposited under euxinic conditions (Kenig et al., 2003). Moreover, Brown and Kenig (2004) observed that the Devonian Ellsworth Shale, Michigan, contains BAQCs in its dominant gray and green shale facies but not in the interbedded laminated black shale beds. These correlations now appear to be artifacts related to samples with low organic yields. Generally, in geological material with low organic extract yields, such as metasediments or sedimentary rocks with low TOC, anthropogenic hydrocarbons can be proportionally more significant than in samples with higher extract yields. These contaminants may remain below detection limits in an adjacent organic-rich material because they are obscured by greater quantities of indigenous organic compounds. Moreover, different types of lithology may have different adsorption properties and varying degrees of porosity, permeability or fracturing. Contaminants in different types of rocks will experience different degrees of evaporation, oxidation, biodegradation and diffusion into fissures, significantly altering molecular ratios. Therefore, caution needs to be exercised when using co-variation of biomarker signals with TOC, extract yields or lithology as an argument for syngeneity.

\subsection{Biomarkers released from kerogen}

Biomarkers that are covalently bound to kerogen are most likely to be syngenetic because they are part of an immobile, autochthonous organic phase. Even early 
incorporation of mobile lipids into proto-kerogen can be assumed to be syngenetic on geological time-scales. Nonetheless, hydrocarbons detected in pyrolysates or chemical degradation products of kerogen are not necessarily indigenous. The discovery of BAQCs and other polyethylene by-products in pyrolysates of pre-extracted kerogens from Toarcian shales (Flaviano et al., 1994), and in $200^{\circ} \mathrm{C}$ hydrogenolysis products of pre-extracted Precambrian massive sulfides, black shales and Shungit coals (Mycke et al., 1988), demonstrates that pyrolysis may release adsorbed hydrocarbons even from apparently clean kerogens. BAQCs were also detected in pyrolysates of bacterial cell wall material (Flaviano et al., 1994), and in pyrolysates of algaenan that was obtained after extensive organic solvent extractions, saponification and acid treatment of algal cell material (Derenne et al., 1996). The observation that preextracted organic matter may retain adsorbed volatiles was confirmed by hydropyrolysis experiments on metamorphosed Archean shale (Brocks et al., 2003b). Brocks et al. (2003b) demonstrated that even 8 steps of extraction with methanol, dichloromethane and hexane, and two steps of swelling of the kerogen with pyridine to open inaccessible space, were insufficient to remove all petroleum contaminants. Only a thermal desorption step in the hydropyrolysis reactor with a stream of hydrogen gas at $325^{\circ} \mathrm{C}$ removed all these residues, and the subsequent high temperature hydropyrolysis step $\left(520^{\circ} \mathrm{C}\right)$ finally revealed that the Archean kerogen was devoid of indigenous, kerogen-bound hydrocarbons. Therefore, regular pyrolysis or chemical degradation experiments do not prove syngeneity unless all non-covalent components have been demonstrably removed from the kerogen or, alternatively, it can be shown that the products were genuinely cleaved from the kerogen (e.g. Murray et al., 1998). Polyethylene derived hydrocarbons, such as BAQCs now provide an excellent tool to decipher whether residual bitumen or petroleum contaminants are still present in pyrolysates even after pre-extraction of the kerogen.

\subsection{Implications for extra-terrestrial samples?}

As many biological lipids are assembled by acetogenic biosynthetic pathways in units of two carbon atoms, odd or even carbon number preferences have been discussed as indicators for biogenicity (Kenig et al., 2005; Simoneit, 2005). Detection of molecules with 'a preference of even or odd numbers of carbon atoms' and 'the presence of polymers based on repeating universal subunits' are also cited as strategies for the search of life on Mars (Committee on an Astrobiology Strategy for the Exploration of Mars, 2007). However, the hydrocarbon by-products of polyethylene production, such as BAQCs and alkylcyclopentanes, are generated by radical chain reactions of $\mathrm{C}_{2}$ ethylene units and also show pronounced odd-over-even or even-over-odd carbon number preferences (Takahashi et al., 1980a,b) (e.g. Figs. $4 \mathrm{~B}$ and $8 \mathrm{~A}$ ). Therefore, carbon number preference is not an exclusive fingerprint for biogenic organic matter.

Reports of hydrocarbons from meteorites have been discussed and reviewed since the 1960s (Hayes, 1967). However, the presence and origin of alkanes and isoprenoids in meteorites has remained controversial. Early work by Oro et al. (1966) showed that the Orgueil meteorite had a greater abundance of hydrocarbons on the exterior and that hydrocarbons decreased in abundance in the interior. Moreover, using isotopic analysis of individual $n$-alkanes, Sephton et al. (2001) showed that $n$-alkanes in meteorites appear to be terrestrial in origin. However, this view have been challenged by Kissin (2003). Although both petrogenic and biogenic molecules have been considered as potential sources for contamination, it is quite likely that the storage medium also often imparts hydrocarbons. Our methodology to compare plastic by-products in exterior and interior rocks can be equally applied to meteorites and may provide further insight into the source of hydrocarbons in these samples.

\subsection{Suggested guidelines for sample analysis and interpretation of syngenetic signatures}

1. For collection and storage of rocks that were potentially already contaminated e.g. during drilling or previous storage, we suggest the use of polyethylene bags. The distribution of BAQCs in the rock may later give information about the extent of hydrocarbon permeation. Rocks that are freshly collected from outcrop or at a drilling site should be dried and wrapped in pre-combusted aluminum foil. However, aluminum foil is not suitable for samples with a high pyrite content. Eventual oxidation of sulfides will release sulfuric acid leading to the decomposition of the aluminum. Soil, sediment and rock powder are ideally stored in pre-combusted glass jars topped with combusted aluminum foil or a cleaned Teflon liner. The concentration of contaminants in different types of plastic bags may vary substantially, and it is critical to test the hydrocarbon content and extractable organic compound distributions before choosing sample storage bags.

2. System blanks that capture the preparation of rocks and all analytical procedures are critical to assess the level of laboratory background contamination. We recommend quantifying the laboratory background by computing 'extract/blank ratios', the concentration of individual biomarkers in the rock or sediment relative to the corresponding blank. Biomarkers with extract/blank ratios below 10 , or better 20 , should be interpreted with caution. For extract/blank ratios below this range, individual compounds in the blank may interfere with computed biomarker ratios. In this case, concentrations in the blank can be subtracted from the sample.

3. Surficial cleaning of rock with solvents is ineffective. Therefore, removal of exterior rock surfaces is required.

4. Contaminants that permeated a rock can be identified by separate analysis of exterior and interior sections. The presence of BAQCs, even-numbered alkylcyclopentanes and other plastic components in the rock interior indicates that a sample was permeable to hydrocarbons, and that petrogenic contaminants may be present in the interior as well. A detailed and quantitative comparison of hydrocarbons in the interior and exterior extracts can then help to identify indigenous components. 
5. A comparison of the concentration profile of BAQCs with other hydrocarbons in a rock can be used to identify traces of contaminants even in complex mixtures of indigenous and non-indigenous material ('slice extraction experiments').

6. Within a sedimentary sequence, absolute and relative concentrations of contaminant hydrocarbons may show covariation with lithology, extract yields or TOC. Therefore, caution needs to be exercised when using co-variation of biomarker signals with rock properties as an argument for syngeneity.

7. Syngenetic hydrocarbons must have a thermal maturity that is consistent with the thermal history of the host rock.

8. Hydrocarbons can be strongly absorbed and adsorbed by kerogen and are not easily removed by simple solvent extraction. Therefore, compounds detected in pyrolysates, even of pre-extracted kerogens, are not necessarily indigenous. However, the presence of BAQCs in pyrolysates may help to detect desorbed petroleum contaminants and residual indigenous bitumen.

\section{CONCLUSIONS}

As BAQCs have similar chemical and physical properties to many hydrocarbon biomarkers naturally occurring in bitumen, they can be used to assess whether a rock or core was infiltrated by anthropogenic petroleum products. This is particularly important for the analysis of samples with low extract yields and for the examination of first occurrences of various biomarker classes in the geological record. The results also suggest a new way to assess hydrocarbons in meteorites.

\section{ACKNOWLEDGMENTS}

This study was funded through the Harvard Milton Fund and Australian Research Council Grant DP0557499. We thank Geoscience Australia (GA) and Roger Summons for access to laboratory space and instruments, Janet Hope and Neel Jinadasa, for technical assistance, and Heinz Wilkes and an anonymous reviewer for constructive comments of an earlier version of this manuscript. E.G. and G.A.L. publish with permission of the CEO of GA.

\section{REFERENCES}

Bai Y., Fang X., Wang Y., Kenig F., Chen X. and Wang Y. (2006) Branched alkanes with quaternary carbon atoms in Chinese soils: potential environmental implications. Chin. Sci. Bull. 51, 1115.

Bennett B. and Larter S. R. (2000) Polar non-hydrocarbon contaminants in reservoir core extracts. Geochem. Trans. 1, 34.

Blau K. and King G. S. (1978) Handbook of Derivatives for Chromatography. Heyden and Son, London.

Boreham C. J., Crick I. H. and Powell T. G. (1988) Alternative calibration of the Methylphenanthrene Index against vitrinite reflectance: application to maturity measurements on oils and sediments. Org. Geochem. 12, 289-294.

Brocks J. J. (2001) Molecular Fossils in Archean Rocks. Ph.D. Thesis, The University of Sydney.
Brocks J. J. and Pearson A. (2005) Building the biomarker tree of life. In Reviews in Mineralogy and Geochemistry, vol. 59 (ed. J. Banfield et al.). The Mineralogical Society of America, Chantilly, pp. 233-258.

Brocks J. J. and Summons R. E. (2004) Sedimentary hydrocarbons, biomarkers for early life. In Treatise on Geochemistry. Vol 8: Biogeochemistry (ed. W. H. Schlesinger). Elsevier-Pergamon, Oxford, pp. 63-115.

Brocks J. J., Logan G. A., Buick R. and Summons R. E. (1999) Archean molecular fossils and the early rise of eukaryotes. Science 285, 1033-1036.

Brocks J. J., Buick R., Logan G. A. and Summons R. E. (2003a) Composition and syngeneity of molecular fossils from the 2.78-2.45 billion year old Mount Bruce Supergroup, Pilbara Craton, Western Australia. Geochim. Cosmochim. Acta 67, 4289-4319.

Brocks J. J., Love G. D., Snape C. E., Logan G. A., Summons R. E. and Buick R. (2003b) Release of bound aromatic hydrocarbons from late Archean and Mesoproterozoic kerogens via hydropyrolysis. Geochim. Cosmochim. Acta 67, 15211530.

Brocks J. J., Love G. D., Summons R. E., Knoll A. H., Logan G. A. and Bowden S. A. (2005) Biomarker evidence for green and purple sulphur bacteria in a stratified Paleoproterozoic sea. Nature 437, 866-870.

Brown T. C. and Kenig F. (2004) Water column structure during deposition of Middle Devonian-Lower Mississippian black and green/gray shales of the Illinois and Michigan Basins: a biomarker approach. Palaeogeogr. Palaeoclimatol. Palaeoecol. 215, 59-85.

Carlson R. M. K. and Chamberlain D. E. (1985) Steroid biomarker-clay mineral adsorption free energies: implication to petroleum migration indices. Org. Geochem. 10, 163-180.

Committee on an Astrobiology Strategy for the Exploration of Mars, and National Research Council. (2007) An Astrobiology Strategy for the Exploration of Mars. The National Academies Press, Washington, pp. 130.

Crick I. H., Boreham C. J., Cook A. C. and Powell T. G. (1988) Petroleum geology and geochemistry of Middle Proterozoic McArthur Basin, northern Australia. II: Assessment of source rock potential. AAPG Bull. 72, 1495-1514.

Derenne S., Largeau C. and Berkaloff C. (1996) First example of an algaenan yielding an aromatic-rich pyrolysate. Possible geochemical implications on marine kerogen formation. Org. Geochem. 24, 617-627.

Donnelly T. H. and Jackson M. J. (1988) Sedimentology and geochemistry of a mid-Proterozoic lacustrine unit from northern Australia. Sediment. Geol. 58, 145-169.

Durand B. (2003) A history of organic geochemistry. Oil Gas Sci. Technol. 58, 203-231.

Espitalié J., Laporte J. L., Madec M., Marquis F., Leplat P. and Paulet J., et al. (1977) Méthode rapide de caractérisation des roches mères, de leur potentiel pétrolier et de leur degré d'évolution. Rev. Inst. Français Pétroll. 32, 23-42.

Flaviano C., Le Berre F., Derenne S., Largeau C. and Connan J. (1994) First indications of the formation of kerogen amorphous fractions by selective preservation. Role of non-hydrolysable macromolecular constituents of Eubacterial cell walls. Org. Geochem. 22, 759.

Fries E. and Püttmann W. (2002) Analysis of the antioxidant butylated hydroxytoluene (BHT) in water by means of solid phase extraction combined with GC/MS. Water Res. 36, 2319 2327.

George S. C. (1992) Effect of igneous intrusion on the organic geochemistry of a siltstone and an oil shale horizon in the Midland Valley of Scotland. Org. Geochem. 18, 705-723. 
Gorter J. D. (1998) The role of ESSO Univis J-26 and similar substances in source rock contamination 1986 to 1992. PESA J. 26, 52-62.

Greenwood P. F. (2006) GC-MS correlation of $\mathrm{C}_{3 n}$ series of naturally occurring highly branched alkanes and polypropylene oligomers. Org. Geochem. 37, 755.

Greenwood P. F., Arouri K. R., Logan G. A. and Summons R. E. (2004) Abundance and geochemical significance of $\mathrm{C}_{2 n}$ dialkylalkanes and highly branched $\mathrm{C}_{3 n}$ alkanes in diverse Mesoand Neoproterozoic sediments. Org. Geochem. 35, 331-346.

Grenacher S. and Guerin P. M. (1994) Inadvertent introduction of squalene, cholesterol, and other skin products into a sample. $J$. Chem. Ecol. 20, 3017-3025.

Grosjean E. and Logan G. A. (2007) Incorporation of organic contaminants into geochemical samples and an assessment of potential sources: examples from Geoscience Australia marine survey S282. Org. Geochem. 38, 853.

Haider N. and Karlsson S. (2002) Loss and transformation products of the aromatic antioxidants in MDPE film under long-term exposure to biotic and abiotic conditions. J. Appl. Polym. Sci. 85, 974-988.

Hart G. A. and Fisher S. J. (1998) Petroleum geochemistry of crude oil contaminated with NovaPlus. PESA J. 26, 40-51.

Hayes J. M. (1967) Organic constituents of meteorites - a review. Geochim. Cosmochim. Acta 31, 1395-1440.

Hunt J. M., Philp R. P. and Kvenvolden K. A. (2002) Early developments in petroleum geochemistry. Org. Geochem. 33, 1025.

Jackson M. J., Powell T. G., Summons R. E. and Sweet I. P. (1986) Hydrocarbon shows and petroleum source rocks in sediments as old as 1.7 billion years. Nature 322, 727-729.

Jackson M. J., Muir M. D. and Plumb K. A. (1988) Geology of the southern McArthur Basin. Bull. Miner. Resour. Geol., Geophys. Aust. Bull., 220.

Kenig F., Simons D.-J. H., Crich D., Cowen J. P., Ventura G. T. and Rehbein-Khalily T., et al. (2003) Branched aliphatic alkanes with quaternary substituted carbon atoms in modern and ancient geologic samples. Proc. Natl. Acad. Sci. USA 100, 12554-12558.

Kenig F., Simons D.-J. H., Critch D., Cowen J. P., Ventura G. T. and Rehbein-Khalily T. (2005) Structure and distribution of branched aliphatic alkanes with quaternary carbon atoms in Cenomanian and Turonian black shales of Pasquia Hills (Saskatchewan, Canada). Org. Geochem. 36, 117-138.

Kissin Y. V. (2003) Hydrocarbon components in carbonaceous meteorites. Geochim. Cosmochim. Acta 67, 1723.

Kvalheim O. M., Christy A. A., Telnaes N. and Bjorseth A. (1987) Maturity determination of organic matter in coals using the methylphenanthrene distribution. Geochim. Cosmochim. Acta 51, 1883.

Logan G. A., Hinman M. C., Walter M. R. and Summons R. E. (2001) Biogeochemistry of the $1640 \mathrm{Ma}$ McArthur River (HYC) lead-zinc ore and host sediments, Northern Territory, Australia. Geochim. Cosmochim. Acta 65, 2317-2336.

Mikami N., Gomi H. and Miyamoto J. (1979) Studies on degradation of 2,6-di-tert-butyl-4-methylphenol (BHT) in the environment. Part I: Degradation of ${ }^{14} \mathrm{C}-\mathrm{BHT}$ in soil. Chemosphere 5, 305-310.

Moldowan J. M., Dahl J. E. P., Huizinga B. J., Fago F. J., Hickey L. J. and Peakman T. M., et al. (1994) The molecular fossil record of oleanane and its relation to angiosperms. Science $\mathbf{2 6 5}$, 768-771.
Murray I. P., Love G. D., Snape C. E. and Bailey N. J. L. (1998) Comparison of covalently-bound aliphatic biomarkers released via hydropyrolysis with their solvent-extractable counterparts for a suite of Kimmeridge clays. Org. Geochem. 29, 1487-1505.

Mycke B., Michaelis W. and Degens E. T. (1988) Biomarkers in sedimentary sulfides of Precambrian age. Org. Geochem. 13, 619-625.

Newton I. D. (1993) The separation and analysis of additives in polymers. In Polymer Characterisation (eds. B. J. Hunt and M. I. James). Springer, Berlin, pp. 8-36.

Oehler J. H. (1977) Irreversible contamination of Precambrian kerogen by ${ }^{14} \mathrm{C}$-labelled organic compounds. Precambrian Res. 4, 221-227.

Oro J., Nooner D. W. A. Z. and Wikstrom S. A. (1966) Paraffinic hydrocarbons in the Orgueil, Murray, Mokoia and other meteorites. Life Sci. Space Res. 4, 63-100.

Pratt L. M., Summons R. E. and Hieshima G. B. (1991) Sterane and triterpane biomarkers in the Precambrian Nonesuch Formation, North American Midcontinent Rift. Geochim. Cosmochim. Acta 55, 911-916.

Radke M. and Welte D. H. (1983) The Methylphenanthrene Index (MPI): a maturity parameter based on aromatic hydrocarbons. Advances in Organic Geochemistry. John Wiley and Sons, New York.

Sephton M. A., Pillinger C. T. and Gilmour I. (2001) Normal alkanes in meteorites: molecular $\delta^{13} \mathrm{C}$ values indicate an origin by terrestrial contamination. Precambrian Res. 106, 4758.

Sherman L. S., Waldbauer J. R. and Summons R. E. (2007) Improved methods for isolating and validating indigenous biomarkers in Precambrian rocks. Org. Geochem. 38, 19872000.

Simoneit B. R. T. (2005) A review of current applications of mass spectrometry for biomarker/molecular tracer elucidations. Mass Spectrom. Rev. 24, 719-765.

Sinninghe Damsté J. S., Muyzer G., Abbas B., Rampen S. W., Massé G. and Allard W. G., et al. (2004) The rise of the rhizosolenid diatoms. Science 304, 584-587.

Summons R. E., Powell T. G. and Boreham C. J. (1988a) Petroleum geology and geochemistry of the Middle Proterozoic McArthur Basin, northern Australia. III. Composition of extractable hydrocarbons. Geochim. Cosmochim. Acta 52, $1747-1763$.

Summons R. E., Brassell S. C., Eglinton G., Evans E., Horodyski R. J. and Robinson N., et al. (1988b) Distinctive hydrocarbon biomarkers from fossiliferous sediments of the Late Proterozoic Walcott Member, Chuar Group, Grand Canyon, Arizona. Geochim. Cosmochim. Acta 52, 2625-2637.

Takahashi M., Satoh T. and Toya T. (1980a) Oligoethylenes in high pressure polyethylenes. I. Identification of homologues. Polym. Bull. 2, 215-220.

Takahashi M., Satoh T. and Toya T. (1980b) Oligoethylenes in high pressure polyethylenes. II. Production mechanism. Polym. Bull. 2, 643-650.

Wenger L. M., Davis C. L., Evensen J. M., Gormly J. R. and Mankiewicz P. J. (2004) Impact of modern deepwater drilling and testing geochemical evaluations. Org. Geochem. 35, 15271536. 